Progress in IS

Yesha Sivan Editor

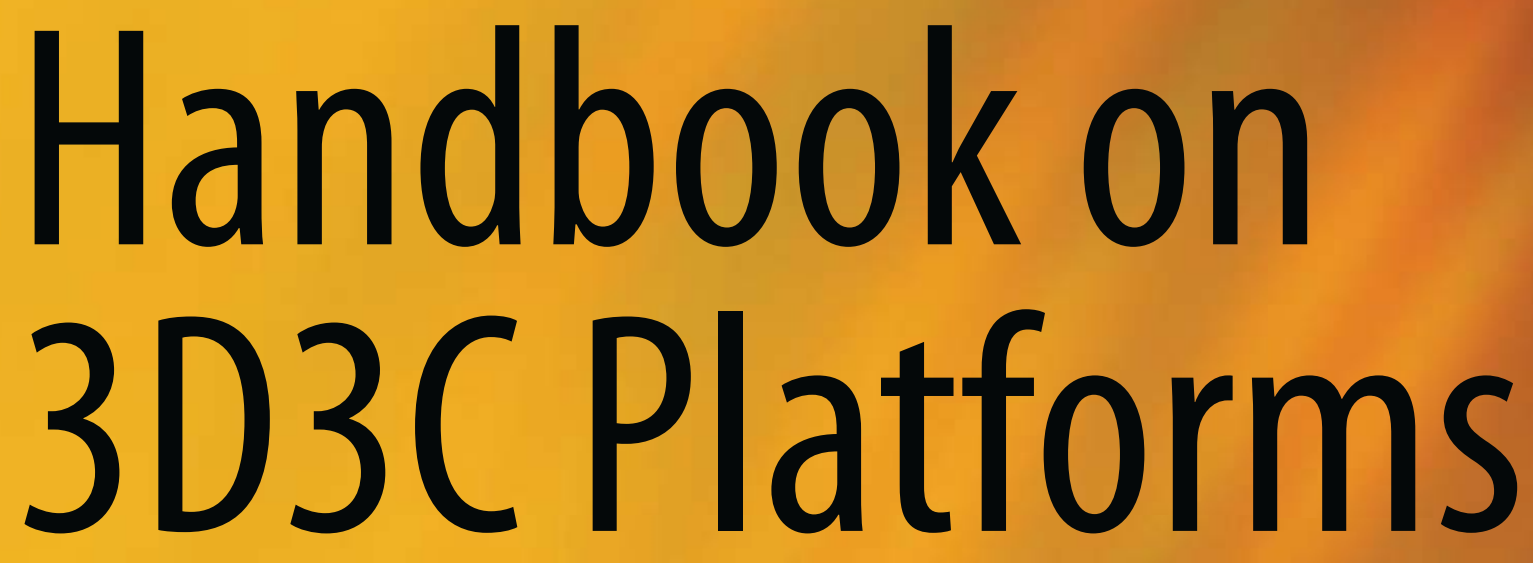

Applications and Tools for Three Dimensional Systems for Community, Creation and Commerce 
Yesha Sivan

Editor

\section{Handbook on 3D3C Platforms}

Applications and Tools for Three

Dimensional Systems for Community,

Creation and Commerce

黛 Springer 


\section{Contents}

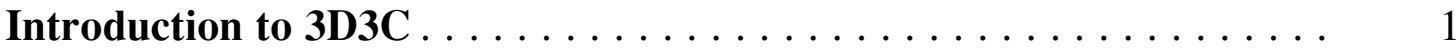
Yesha Sivan

\section{Part I Tools}

The Raise of the Robots in Virtual Worlds: A Comparison and a Framework for Investigating Bots in Social Networks Sites

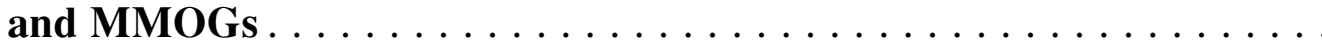

Stefano De Paoli

United States Taxation of Virtual World Economies: A Review of the Current Status

Jamie S. Switzer and Ralph V. Switzer

Virtual Worlds Supporting Collaborative Creativity

Pekka Alahuhta, Anu Sivunen, and Teemu Surakka

Virtual Currencies, Micropayments and Monetary Policy:

Where Are We Coming From and Where Does the Industry Stand? . . .

Ruy Alberto Valdes-Benavides and Paula Lourdes Hernandez-Verme

Privacy in Virtual Worlds: A US Perspective to a Global Concern . . .

Jeannie Pridmore and John Overocker

Avatars and Behavioral Experiments: Methods for Controlled

Quantitative Social Behavioral Research in Virtual Worlds

Dimitrij (Mitja) Hmeljak and Robert L. Goldstone

Review of Educational Research Methods in 3D3C Worlds:

Framing the Past to Provide Future Direction .

Dennis Beck and Ross A. Perkins

Linguistic and Multilingual Issues in 3D3C Worlds

Samuel Cruz-Lara, Alexandre Denis, Nadia Bellalem, and Lotfi Bellalem 


\section{Part II Applications}

The Virtual Experience Economy: A Service-Dominant Logic

Perspective

Eman Gadalla, Kathy Keeling, and Ibrahim Abosag

Virtual Psychology: An Overview of Theory, Research, and Future

Possibilities

Jennifer $\mathrm{Wu}$ and Philipp Kraemer

Virtual Worlds for Energy: A Topical Review.

Nick V. Flor and Olga Lavrova

Simulating History in Virtual Worlds

Nicola Lercari

Virtual Reality in Medicine

Claudio Pensieri and Maddalena Pennacchini

Computer-Simulated 3D Virtual Environments in Collaborative

Learning and Training: Meta-Review, Refinement, and Roadmap . .

António Correia, Benjamim Fonseca, Hugo Paredes, Paulo Martins, and Leonel Morgado

Computational Ecosystems in Evolutionary Art, and Their Potential for the Future of Virtual Worlds

Rui Filipe Antunes, Frederic Fol Leymarie, and William Latham

Finding Healthcare Support in Online Communities: An Exploration of the Evolution and Efficacy of Virtual Support Groups . . . . . . . . . .

Donna Z. Davis and Willemien Calitz

Virtual Fashion as an Industry: Making the World Look Better

One Avatar at a Time . . . . . . . . . . . . . . . . . . . . .

Phylis Johnson 

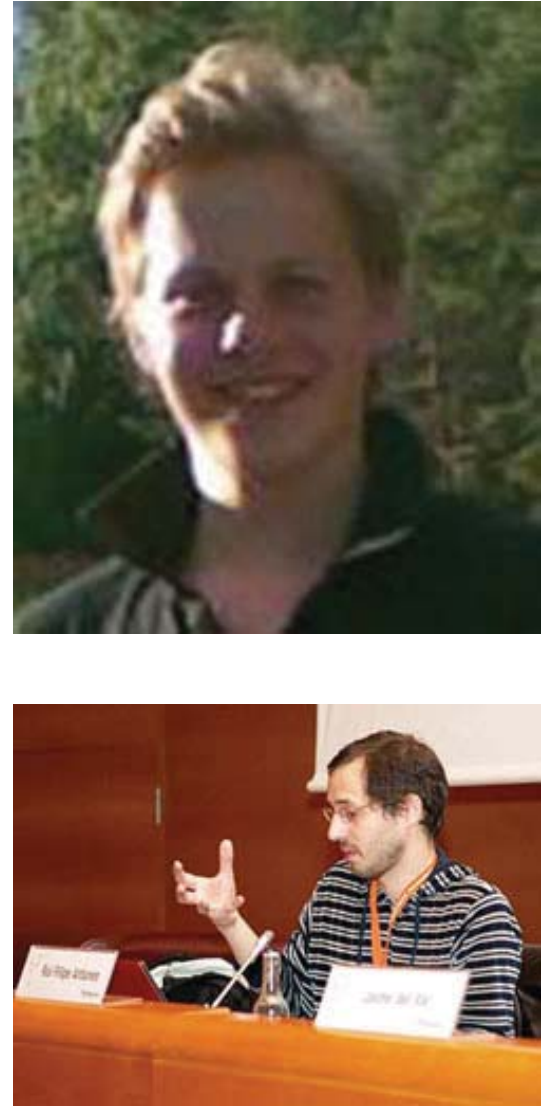

Pekka Alahuhta is a researcher and Ph.D. student in the Department of Industrial Engineering and Management at Aalto University School of Science, Finland. His research interests are directed to computer-mediated communication and practices that support distributed teams' creative activities.

Rui Filipe Antunes has recently completed a Ph.D. in generative animation at Goldsmiths, University of London, with sponsorship by Fundação para a Ciência e Tecnologia in Portugal.

His work has been awarded twice in VIDA, the international competition of art and artificial intelligence (12th and 13th editions), and features in publications such as Preble's Artforms and Leonardo. A large number of curatorial projects and shows have featured his work, including the International Festival of Digital Art at Waterman's, the
rs anniversary of the AISB, and a solo show at the Tin Shed A-Eye exhibition celebrating the 50 years anniversary of the AISB, and a solo show at the Tin Shed gallery in London, UK. In 2009, his work featured in the exhibition Lá Fora at Museu da Electricidade, in Lisbon, Portugal, a perspective of historical and contemporary art by Portuguese living abroad.

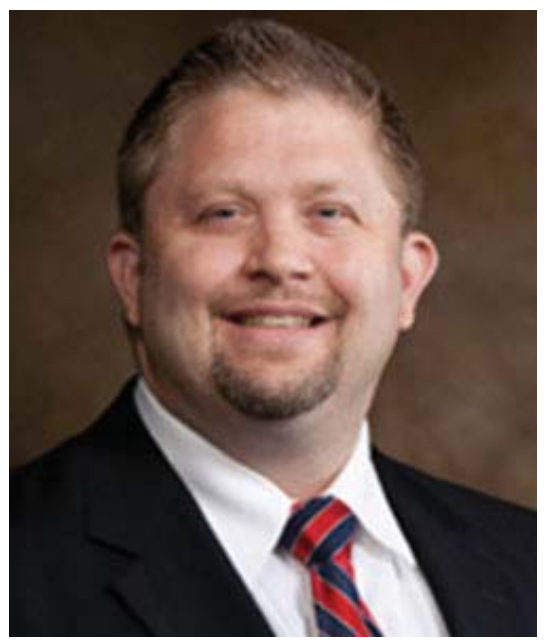

Dennis Beck is an Assistant Professor of Educational Technology at the University of Arkansas. He enjoys teaching courses in instructional design, integrating technology into the curriculum, and educational technology research. $\mathrm{He}$ also has a wealth of experience in the design of online and blended courses in educational and corporate training environments.

He has researched and written about K-12 virtual schooling for special education students and virtual school leaders, as well as the influence of avatar-based simulations and games on stigma experienced by students and teachers. Of special interest is his exploration of the influence of avatar-based simulations on stigma experienced by teachers and students. He is currently working on a study exploring the influence of teacher avatars on student evaluations. He has published in several other venues, including Computers \& Education, American Journal of Distance Education, Educational Administration Quarterly, Journal of Educational Research, and the Journal of Virtual Worlds Research. 


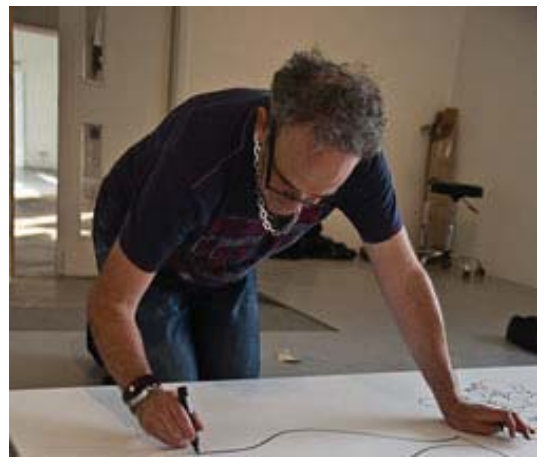

William Latham is a pioneer of digital art and is well known for his evolutionary computer art at IBM Research from 1987 to 1993 . His work was widely shown in internal touring exhibitions to Japan, Australia, and Germany sponsored by the British Council. He was then Creative Director of leading UK Games Development Studio Computer Artworks Ltd for 10 years, creating computer games published by Universal Studios, Warner Interactive, and Microsoft. William was then MD of consultancy company Games Audit Ltd whose clients included IFG (part of Allianz Insurance) and Malta Enterprise. At Goldsmiths since 2007, his research projects include an Innovate UK award into procedural architecture. He is a colead with Prof Fol Leymarie on an exciting serious games research project into protein docking with Imperial College Bioinformatics Department funded by the BBSRC. His recent Mutator $1+$ 2 Exhibition sponsored by Arts Council England was shown in Brighton and Brussels and is on show in Dundee. He is industrial liaison lead for the IGGI Ph.D. Research Program and is codirector of SoftV Ltd working on games for Neuroscience/health with UCL.

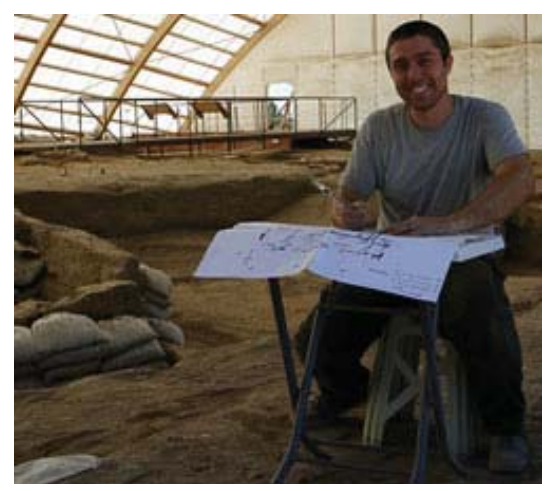

Nicola Lercari is an Assistant Professor of World Heritage at the University of California Merced where he investigates digital methods of heritage preservation, visualization technologies for public history, and the usage of crossmedia systems in museums. Dr. Lercari received his Ph.D. in History and Computing from the University of Bologna, Italy, in 2011 with a dissertation on the visualization of medieval urban spaces in XIII century Bologna (Nu.M.E. project). Nicola has worked on several digital humanities initiatives both in Italy-CINECA supercomputing center and the University of Bologna - and in the United States: at Duke University, Nicola led the development of Venice Virtual World, a narrative-interactive virtual world representing life and cultures in early-modern Venice; at the University of California Merced, Nicola is a founding faculty member of the World Heritage program and he contributed to the development of the serious game for heritage Fort Ross Virtual Warehouse. Dr. Lercari's scholarship explores the analytical role of visualization in the interpretation of the past and its material culture. Specifically, he strives to develop a theoretical framework able to explain the power and cultural value of virtual worlds and serious games in conveying new information about our past, heritage, and societies. 


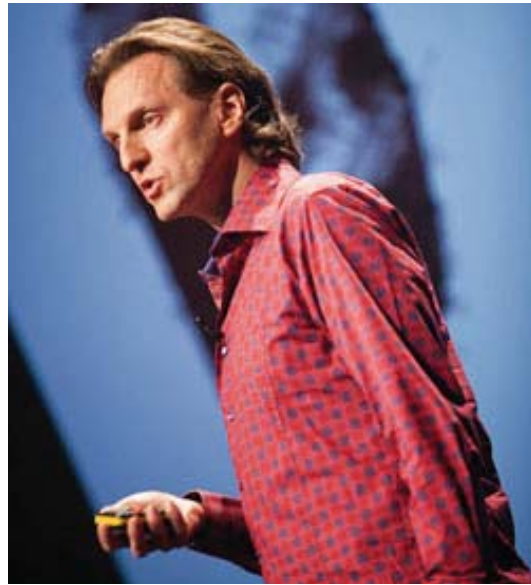

Frederic Fol Leymarie joined the Computing Department at Goldsmiths in mid-2004. He first initiated and directed the M.Sc. Computational Arts and then got William (Latham) to join him at Goldsmiths and initiate the M.Sc. Computer Games and Entertainment (launched in 2008), the first (and leading) industry facing M.Sc. for games programming in the Greater London area (www. gamesgoldsmiths.com).

Frederic is currently co-PI of the BBSRC-funded Docklt gamification research project focused on the fundamental problem of protein docking (how to bring complex 3D protein molecules together in ways that make biological sense). This work is in collaboration with Prof. Latham and Prof. Mike Sternberg at Imperial College. Frederic is also working on modeling the human visual perception of shapes (2D, 3D in movement).

Frederic is a graduate of Brown University, Engineering Division (Ph.D., 2003), McGill University, Centre for Intelligent Machines (M. Engin. 1990), and Ecole Polytechnique of Montreal, Electrical and Aeronautics Engineering (1986). In the 1990s, he spent time between Canada (CIM at McGill) and France (at the School of Mines of Paris and in industry working in the area of 3D Geographical Information Systems). For more details on Frederic, including recent publications, see www.folleymarie.com.

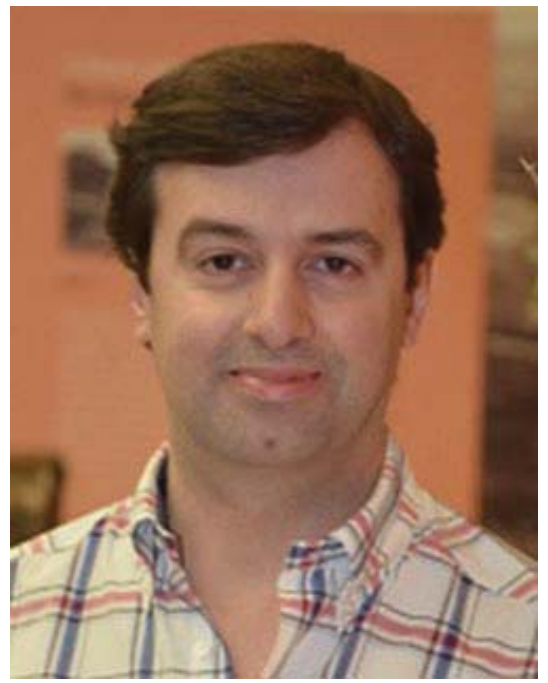

Paulo Martins received a B.Eng. degree in Electric Engineering in 1992 from the University of Trás-os-Montes e Alto Douro (UTAD), Portugal, an M.Eng. degree in Computer and Electric Engineering in 1996 from the University of Porto, Portugal, and a Ph.D. degree in 2005 from UTAD, where he now is an Assistant Professor, lecturing on database systems and programming. His doctoral thesis subject was "A model for distance learning in environments that support mobility." His main research interests are Distance Learning, Technology Enhanced Learning, Mobile Environments, Virtual Worlds, and Data Warehouses, and he has several scientific publications in these fields, in peer-reviewed conferences, journals, and books.

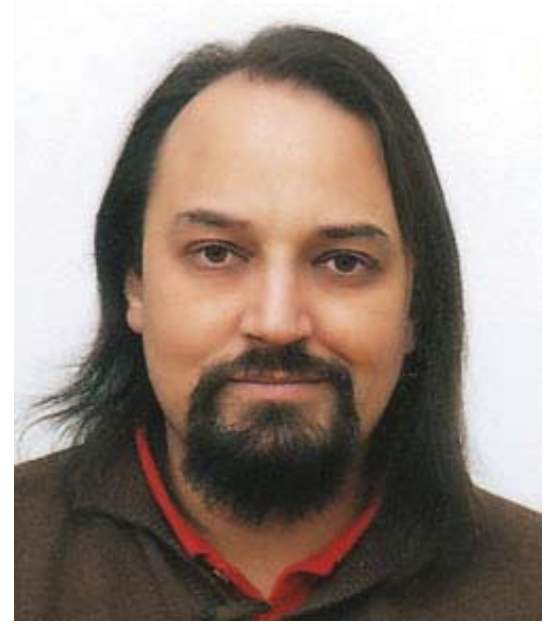

Leonel Morgado is an Invited Assistant Professor with Habilitation at Universidade Aberta, a Portuguese public university based on e-learning, where he lectures on programming and virtual worlds. His main research interest is the use and development of virtual worlds as tools for learning and business, which he pursues since 2000. He authored over 100 papers. Before pursuing an academic career, he was business and technical manager of a private company, terminologist in localization teams (MS Office 97 and Oracle InterOffice), language consultant for IBM/Lotus, coordinator of Web-development and software-deployment teams, and manager of cooperative extension fighting digital divide in villages. 


\title{
Computational Ecosystems in Evolutionary Art, and Their Potential for the Future of Virtual Worlds
}

\author{
Rui Filipe Antunes, Frederic Fol Leymarie, and William Latham
}

\section{Introduction}

The development of computer systems with communities of agents organized as ecosystems is a practice with some already established tradition in the disciplines of Artificial Life (or ALife) (Bisig \& Unemi, 2010; Dorin, 2005) and ecology (Railsback \& Grimm, 2011). In this chapter, we survey from the last two decades such works developed within the more experimental context of the visual arts. This allows us to characterize the field while identifying structural features and ideas that might provide pointers and contribute to the future of Virtual Worlds.

Computational Ecosystems (CEs) are computer programs that simulate interactions of agents inspired by life in nature (Fig. 1). In a typical CE agents are organized in a hierarchical structure (food chain) and a community dynamics is promoted through the trade of token units of energy and biomass between these agents. In ecology CEs are used when modelling carbon-based contexts and can be considered part of the sub-domain of "agent and individual based models" (Railsback \& Grimm, 2011). One of the most well-known example is Daisyworld (Watson \& Lovelock, 1983; Lenton \& Lovelock, 2001), where the numerical simulation drives the population dynamics of two families of plants (daisies) on an earth-like planet by modelling the number of existing individuals (and their features) over generations. In Daisyworld different rhythms and regulation feedbacks are observed as the environmental conditions change or remain stable (such as dictated by the flow of energy from a virtual sun). By contrast, more recent CEs

R.F. Antunes $(\square)$

BioISI, Faculdade de Ciências, Universidade de Lisboa, Lisbon, Portugal

MIRALab, Université de Genève, Geneva, Switzerland

e-mail: rfantunes@fc.ul.pt

F.F. Leymarie • W. Latham

Goldsmiths, University of London, London, UK 
(a)

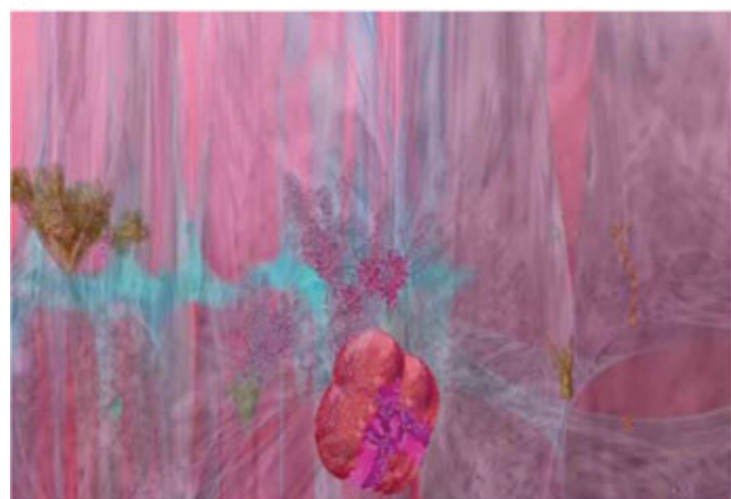

(c)

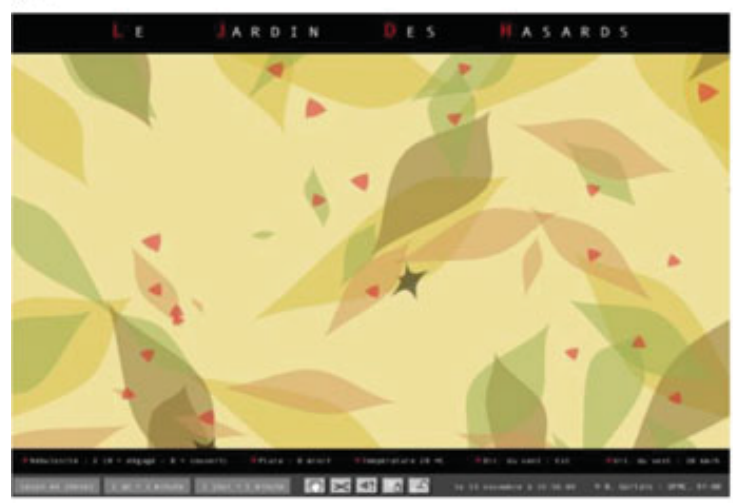

(b)

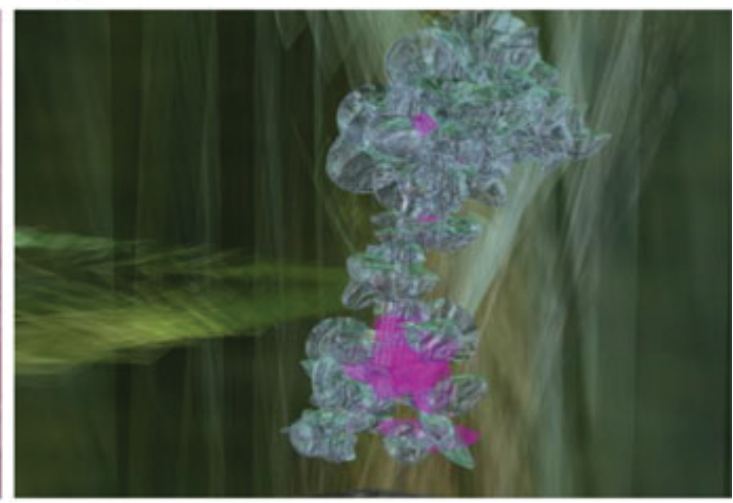

(d)

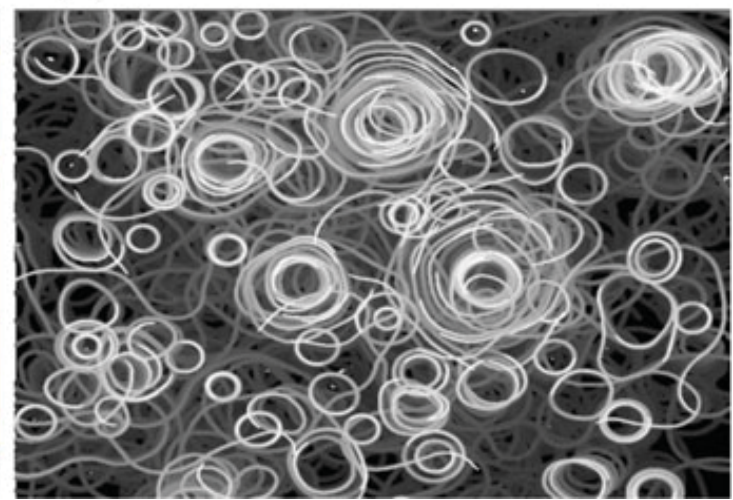

Fig. 1 (a) Still from xTNZ (Antunes \& Leymarie, 2008), a CE in which creatures see their physical features (shapes, textures and sounds) evolve over generations by means of Mendelian genetics and Darwinian natural selection (C Antunes \& Leymarie, 2008). (b) Still from Senhora da Graça (Antunes \& Leymarie, 2010): an evolutionary ecosystem exploring the biological phenomenon of epigenetics, where parametric variables of the system affect the physical traits of the creatures (C) Antunes \& Leymarie, 2010). (c) The Garden of Chances (Hutzler, Gortais, \& Drogoul, 2000): a visual ecosystem where atmospheric variables inform the growth of the virtual entities (@) Hutzler et al., 2000). (d) Swarm paintings, where each individual acts as a brush in a canvas (Bornhofen, Gardeux, \& Machizaud, 2012) (@ Bornhofen, Heudin, Lioret, \& Torrel, 2012)

used in the visual arts are characterized by the agency of the modelled individuals, operating in a logic of autonomy and giving rise to phenomena of self-organization and emergence-i.e. the appearance of new unforeseen structures (Bentley \& Corne, 2002).

The ALife art practice already has a rich history, in particular since the mid-1990s, with innovative works such as Technosphere (Prophet, 1996), Turbulence (McCormack, 1994) or A-Volve (Sommerer \& Mignonneau, 1994). This new art practice has matured through the past two decades and embraced a range of disciplines at the confluence of aesthetic ideas in science and technology, including: kinetic art, generative art, evolutionary art, and aesthetics systems. CEs, as we shall see, play important roles as generative engines in various artistic contexts, including: audio-visual applications (Dorin, 2012), music genesis (Eldridge \& Dorin, 2009) or driving the choreography of avatars in virtual worlds (Antunes \& Leymarie, 2012). 
Metacreations (Whitelaw, 2004), Creative Evolutionary Systems (Bentley \& Corne, 2002), The Art of Artificial Evolution (Romero \& Machado, 2007) and Virtual Worlds (Bornhofen et al., 2012) are some of the key texts in this field. The first is an in-depth critical account of art created with ALife systems, which surveys the theoretical discourses of important works, covering also aspects of the development of CEs. The three other titles provide collections of texts on evolutionary art and virtual worlds, and are mostly technically oriented. In The Art of Artificial Evolution, a chapter by Alan Dorin, entitled "A Survey of Virtual Ecosystems in Generative Electronic Art" provides an overview of art making use of CEs (Romero \& Machado, 2007, Ch. 14). Our research complements these previous works by mapping out this field, and in particular, it extends Dorin's older survey, by virtue of providing a detailed systematization and objective classification of this area of knowledge. We study this area and the various contexts in which works are presented, as well as consider their formal attributes and the user experience qualities. Doing so, we outline patterns and common features which might help to refine and better characterise the field and grasp the uniqueness and creative potential of this practice. In the following section we first look at Evolutionary Art (EvoArt) (Boden \& Edmonds, 2009), an aesthetic domain which includes CEs used in ALife art, and start identifying some of the fundamental features common to these systems.

\subsection{The Three Main Genres of Evolutionary Art}

Evolutionary Art is a form of artistic expression characterized by the instrumentalization of processes of evolution by combining the principle of natural selection (after Darwin and Wallace) with the rules of genetics (after Mendel) in order to promote the creation of artefacts obeying a new aesthetic.

\subsubsection{The First Genre: Gtype-Ptype}

EvoArt encodes a blueprint (the genotype-Gtype) which is then converted to its iconic or audible (or multi-media) representation (the phenotype-Ptype). This approach is borrowed from the framework of Genetic Algorithms (GAs) in Computer Science, where syntactic elements are translated into their semantic interpretation. A community evolves through gene-lead processes. The 'best' in a pool of individuals are chosen to procreate or further evolve. In the process they will blend their successful Gtypes in a new pool of individuals which will replace the old ones. With GAs the fitness criteria determining which individuals are to be kept are problem-dependent.

With traditional EvoArt it is a human operator who controls the selective pressure known as the Interactive GA (or IGA). The complexity of this process of conversion from Gtype to Ptype is open to artistic creativity and the linearity and distance involved in this process of transformation differ widely amongst artists. 


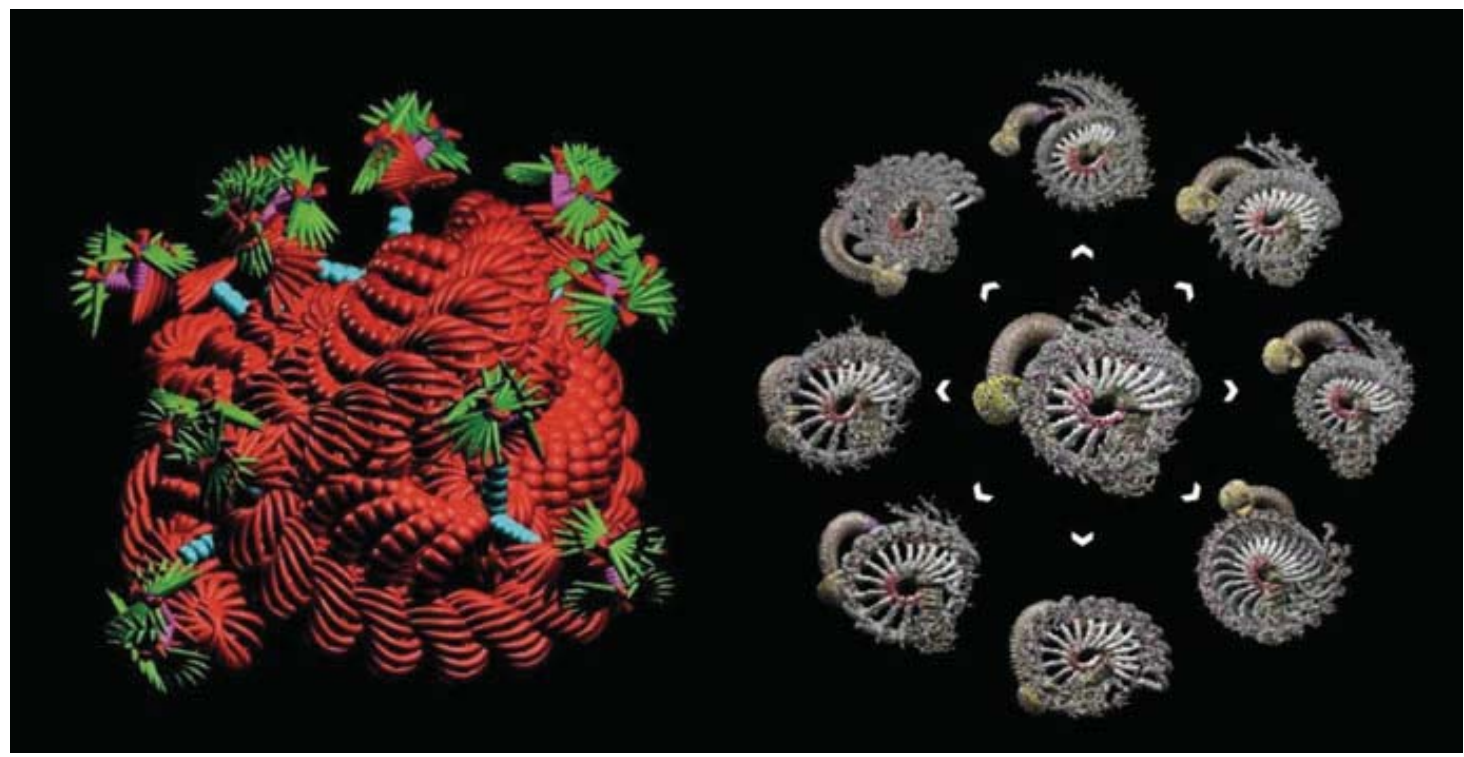

Fig. 2 William Latham uses a grammar of morphological operators and transformations to encode the information contained in the "genomes" of his artefacts (Latham, 1989; Todd \& Latham, 1992). An interactive process of selecting successive genomes generate a series of images (here in 3D) based on a process of recombination and mutation of the genes. At each generative step, the artist selects the preferred of these new images to serve as progeny for the next iteration. On the left is shown one outcome of an EvoArt session: PlantForm (C Latham 1989), and on the right is illustrated one evolutionary step in another session where the central parent, once selected by the artist, is used to create eight new descendants (C) Latham 1991)

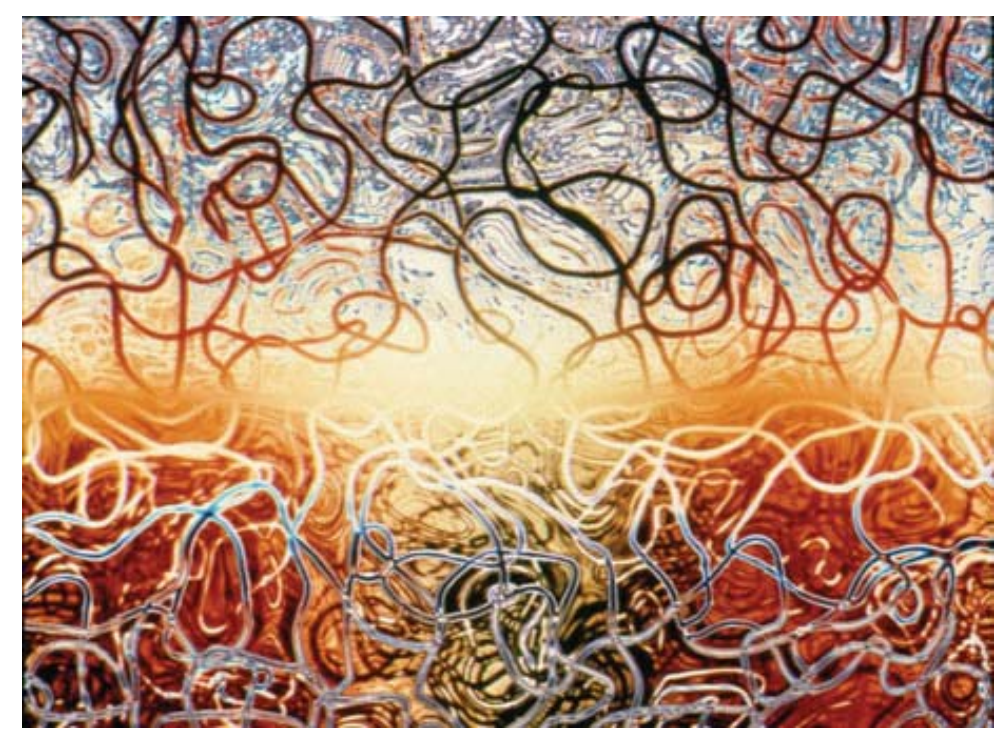

Fig. 3 Extinct Image, Karl Sims, 1990. From “Artificial Evolution for Computer Graphics,” ACM SIGGRAPH'91 Conference Proceedings, Las Vegas, Nevada, July 1991

The diversity of the outcomes this methodology entails is illustrated for example by computational evolutionary art pioneers Latham and Sims: William Latham produces 3D morphologies based on a process of shape deformation (Fig. 2), while Karl Sims generates abstract imagery (Fig. 3) based on a language of mathematical and visual operators (Lambert, Latham, \& Leymarie, 2013; Whitelaw, 2004). 


\subsubsection{The Second Genre: Virtual Communities}

The Gtype-Ptype metaphor has also been explored by applying it to whole populations of interacting autonomous agents defined by CEs. In addition to the Gtype-Ptype translation process, the autonomy of the individuals generates an interesting dynamics of self-organization and emergence with cyclic changes of density. Each of the agents in the community emulates a simplified form of the life cycle of generic carbon-based life forms. In a regular CE, genetic characteristics such as the size or speed of the agents is carried over from parents to children when individuals replicate, in a process that emulates sexual reproduction. The selective pressure is expressed in how well the individuals perform in the system, in order to perpetuate their genetic heritage. Energy might be required for the activities of these individuals, such as moving, running, or simply breathing. The population competes for energy and space, and this dynamic of energy transfer occurs in predatory acts. When the energy level of an individual becomes too low, it is considered dying and removed from the community.

Systems can be distinguished by the way they are organized based on patterns of energetic exchange. A reading of the literature provides us with four dominant models: homogeneous, chemostat, heterogeneous and food-web. We describe these next.

\section{Homogeneous model:}

The simplest model is the one using homogeneous populations (Fig. 4-Hm). Interactions are established within a closed community (i.e. without exterior exchanges) of similar individuals. This is the model used, for instance, in A-Volve (Sommerer \& Mignonneau, 1994). In order to survive in the virtual tank of A-Volve, fishes need to capture other fishes co-inhabiting in the tank. In this type of community the interactions are mainly pre-established during the design stage of production. However, they may also be designed in order to evolve with time, generating dynamic food webs which shrink or expand with the emergent (unforeseen) complexity of the interactions.

2. Chemostat model:

In classical chemostats (or static chemical environments) external input feeds a constant regulated flow of resources to a population of cells or chemical agents (Fig. 4-C). Populations of this type (C) can be characterized as having a sub-population of consumers distinguished from its source of energy. This might be a set of 'food-bits' or a sub-population of producers. These two non-interbreeding groups are usually represented using distinct data-structures. In Genepool (Ventrella, 2005), for instance, dynamic individuals feed on passive 'food-bits'. In general, the sub-population of consumers is used to model heterotrophic individuals, such as carnivores, that mostly rely on other organisms to survive. The source of energy is used to simulate autotrophs, such as green plants, which can manufacture food from their abiotic environment. Tierra (Ray, 1995), and Polyworld (Yaeger, 1994) are classic works which employ this type of design. In GenePool and Polyworld the source of energy is constituted by 


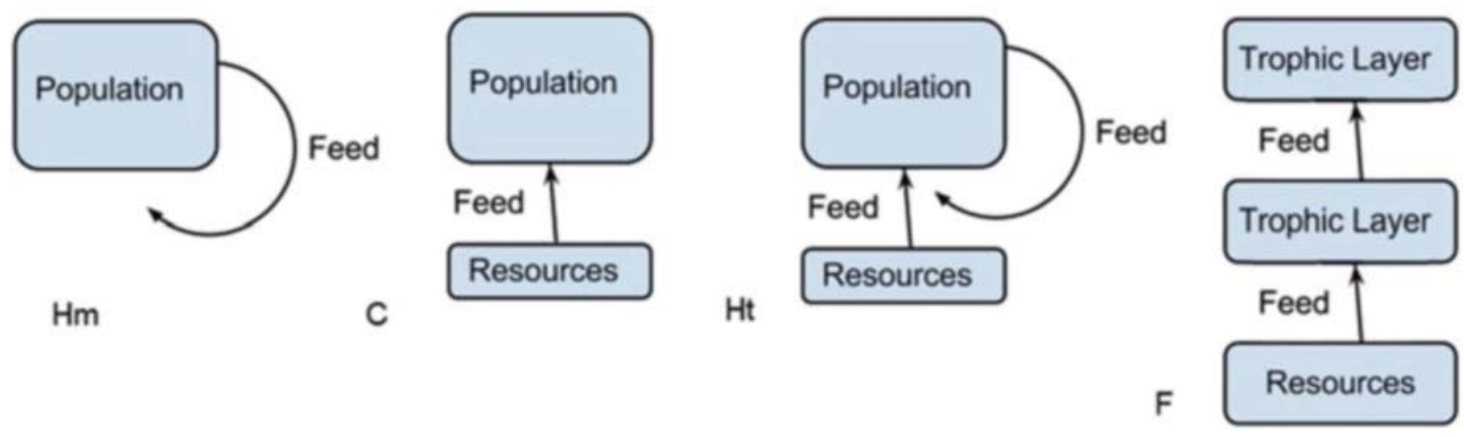

Fig. 4 (Adapted from Antunes' thesis (Antunes, 2014).) Four distinct models of population, from left to right. Hm Homogeneous, $C$ Chemostat, $H t$ Heterogeneous, and $F$ Food web

passive abiotic units which appear, as if by magic, on the surface of the simulated world. Tierra is a special case where individuals compete for units of processing time. Extended derivations from this model creatively play with the flow of energetic input. In Life Spacies II (Sommerer \& Mignonneau, 2000), or Black Shoals (Demos, 2012; Portway, Autogena, Hoile, \& Riley, 2004), the appearance and growth of producers is not constant and infinite as in the previous examples, but rather is dependent on some actions external to the community. Such external inputs are performed either by the public in the installation space, as in the case of Eden (McCormack, 2001) and Life Spacies II (Sommerer \& Mignonneau, 2000), or by some other external factors such as movements of shares on the Stock Exchange, as in Black Shoals (Demos, 2012; Portway et al., 2004), or even variations in the weather as in Garden of Chances (Hutzler et al., 2000).

3. Heterogeneous model:

This model is a combination of the previous two. It describes works where individuals in the population feed not only from an external source but also from other members of their community (Fig. 4-Ht). This is the type of interaction at play in xTNZ (Antunes \& Leymarie, 2008) and Senhora da Graça (Antunes \& Leymarie, 2010). In these CEs, individuals have dietary constraints emulating some form of chemical metabolism, which restricts the range of possible preys. These metabolic constraints force the emergence of multilayer food webs (Saruwatari, Toqunaga, \& Hoshino, 1994) where some individuals are able to exclusively prey on producers, some other individuals are only able to prey on other consumers, while others are able to prey on both producers and consumers.

4. Food-web model:

In contrast to the emergent food webs previously described, in Technosphere (Prophet, 1996) or Eidea (Mitchell \& Lovell, 1995), individual metabolisms and trophic interactions are pre-established (Fig. 4-F). In these projects the ecosystem is typically composed of three different trophic levels that emulate carnivores, herbivores and plants. Here evolutionary forces do not change individual diets as happens with some of the previous models (such as $\mathrm{Hm}$ and $\mathrm{Ht}$ ). Some commercial games, drawing on evolution, make use of this model of 
(a)

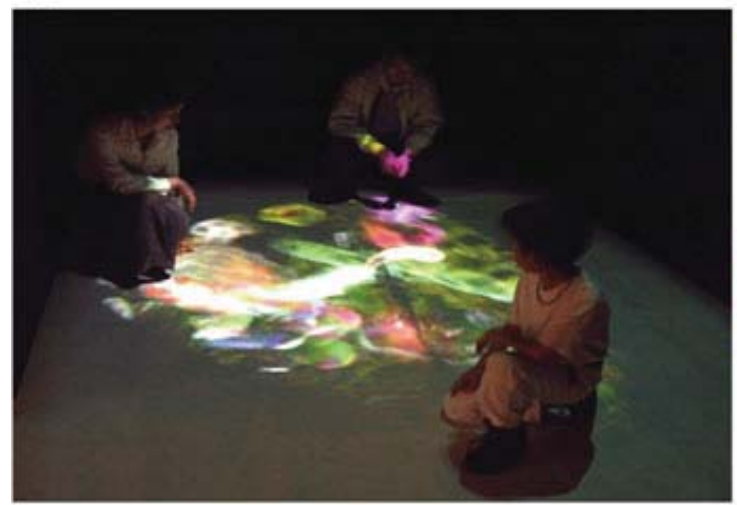

(c)

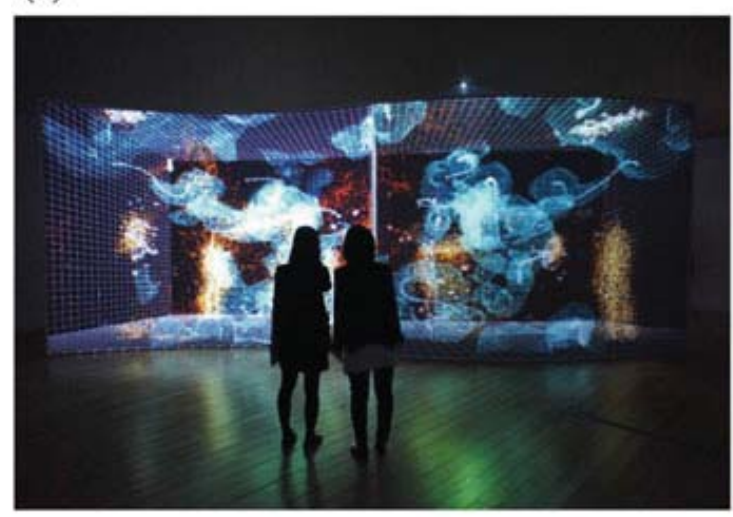

(e)

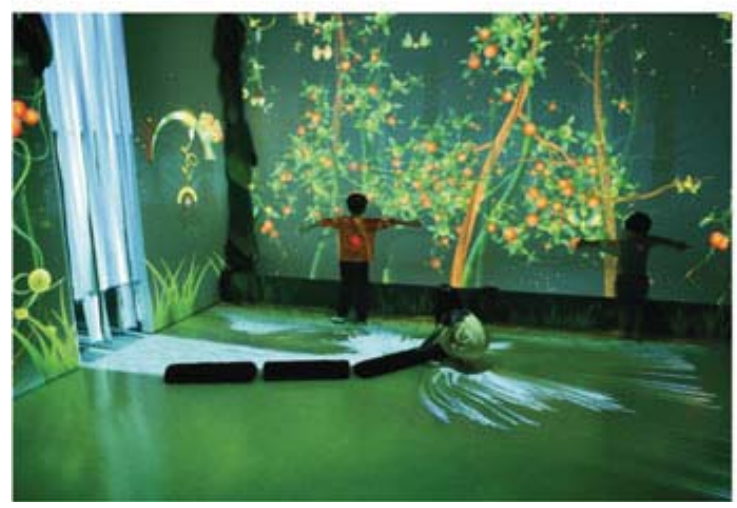

(b)

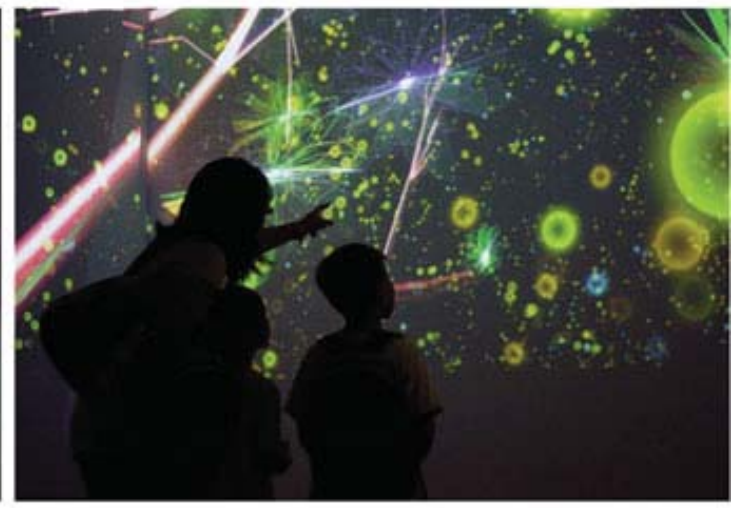

(d)

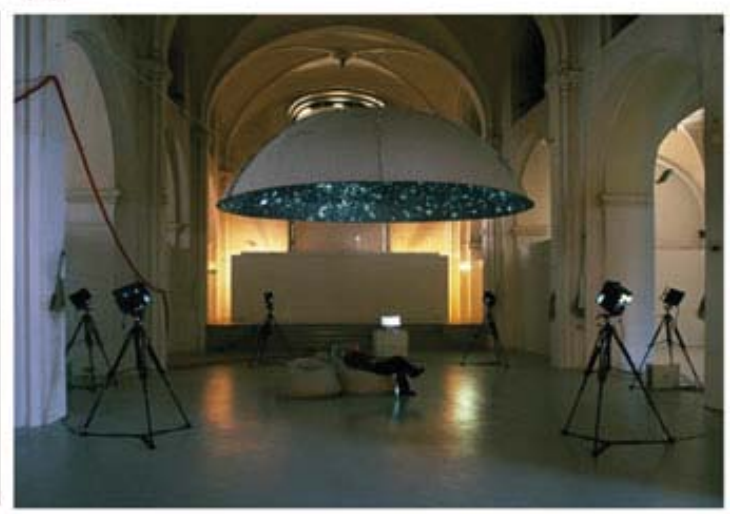

(f)

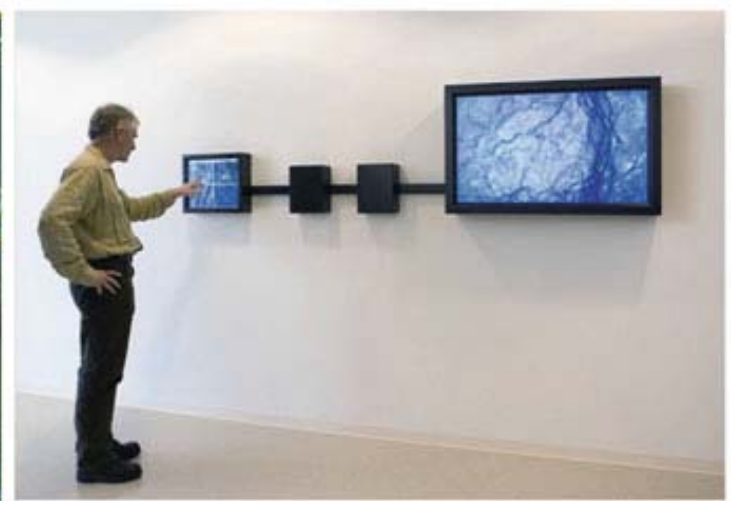

Fig. 5 Various CEs in public exhibition in gallery context: (a) C.-Y. Chen and J.-C. Hoyami: Quorum Sensing (Chen \& Hoyami, 2007), Art Outsiders Festival, Paris, 2002; (b) Haru Ji and Graham Wakefield: FluidSpace, $2009 \mathrm{Ji}$ (2012); (c) Haru Ji and Graham Wakefield: Time of Doubles (Ji, 2012; Wakefield, 2012), 2012; (d) Lise Autogena, Joshua Portway and Cefn Hoiles: Black Schoals (Demos, 2012) at Tate Britain in London, 2002; (e) Emily Gobeille and Theo Watson: Funky Forest (Watson \& Gobeille, 2007), in 2008; (f) Driessens and Verstappen: E-volver (Driessens and Verstappen, 2006), LUMC Leiden, photo Gert Jan van Rooij 2006

community. The procedural creatures of Spore, for instance, have predefined 'metabolic' capabilities and scope (Arts, 2009). The user can only choose where his/her creature will fit in the a-priori rigid hierarchy of the food-chain. 
CEs used in EvoArt are structured upon one of the patterns described above in order to explore processes of self-organization and emergence. As the individuals compete for energy trying to survive and perpetuate their genetic heritage the community becomes increasingly heterogeneous. These processes of selforganization are the main mechanisms used to generate heterogeneity and novelty in the artistic works (Figs. 1 and 5). We have also identified a growing tendency to have Gtypes directly sonified or visualized. Wakefield and Ji, for instance, produce sounds directly from the transcription of the Gtype data (Wakefield \& Ji, 2009).

\subsubsection{The Third Genre: CEs Dynamics-Ephemeral Events, Internal States}

We propose a third genre characterized by artists who are interested in the ephemeral states of the system and the dynamics generated by its individuals, where the system's internal states translate into actions performed by agents. In the work Unfinished Symphonies-songs from a 31/2 worlds we can read: "the rhythm list increases when the creature eats a tree and decreases as it ages or fails to find food". Then, referring to another work: "Each creature starts its life as a soprano [...] having only one body segment and a high pitched voice. When it reaches puberty, it becomes an Alto with one extra body segment and a slightly lower voice. Altos are also able to bear children. Later in life, the alto transforms into a Tenor and then later still becomes a Bass" (Berry, Rungsarityotin, \& Dorin, 2001). Another example is provided by the soundscapes produced by Eldridge and Dorin. These are granular compositions where timbre and pitch depart from the spatial aggregation of the individuals in the virtual environment (Eldridge \& Dorin, 2009). Antunes and Fol Leymarie take advantage of the internal dynamics and the ephemeral states generated by CEs to generate choreographies and animate dancers (Antunes \& Leymarie, 2012) and groups of conversational humanoids (Antunes \& Leymarie, 2013).

Before we present and discuss our survey's results, we describe next the methodological aspects.

\section{Methodology}

\subsection{Domain of the Survey}

To initiate our study we went through the proceedings of the main scientific conferences covering the relevant genres of work, including: EvoMusArt, Generative art, Genetic Evolutionary Computation Conference, the IEEE Congress on Evolutionary Computation, and Artificial Life. We also looked at a collection of established books with surveys on ALife art or EvoArt, including: 
Creative Evolutionary Systems (Bentley \& Corne, 2002), Metacreations (Whitelaw, 2004), The Art of Artificial Evolution (Romero \& Machado, 2007), and Virtual Worlds (Bornhofen et al., 2012). Finally we looked at art magazines such as Art Forum and journals such as the International Journal of Arts and Technology and the Journal of Virtual Worlds Research. From these we have selected a sample of 40 papers. Our aim was not of producing an exhaustive scrutiny of the field, but rather to have a sufficient sample of important works, from which we could derive with good confidence interesting conclusions. On the one hand, this sample should cover the full spectrum of activities with regards to artistic styles and uses of the CE framework, and on the other hand, it should be sufficiently well distributed throughout the 20 years of our set time frame (19932013). We followed two main selection criteria: the art-criterion and the CE-criterion. The first constrained the selection to works that have been presented or discussed as artistic projects, ideally exhibited in a gallery, museum or an art festival or shown/distributed on the internet. The second criterion constrained the selection to instances where the artificial beings that populate the world emulate aspects of biological life forms. This includes works where individuals are: represented by Gtype-seeds, or exchange energy or mass, or emulate metabolic cycles (these might include birth, growing morphologies, reproduction and death). Ideally, works should include all these factors, but due to the variety of approaches, this criterion was loosened to the presence of at least one criterion.

\subsubsection{Surveyed Works}

The list of selected works (in reverse chronological order) is presented in Table 1.

\subsection{Variables and Taxonomy}

To describe the selected works we modified a taxonomy from Carvalhais (2010) who recommends to classify works of generative art via an adaptation of Aarseth's taxonomy for cybertexts (Aarseth, 1997). Our taxonomy includes detailed aspects of the physical implementation of the works in a public exhibition space, while some redundant aspects to the nature of CEs (such as the existence or not of dynamism in the works) are removed. We have divided into three groups the variables used for classification to: (i) describe contextual properties; (ii) capture the user experience; and (iii) describe formal properties. We describe these three groups and there constitutive variables below. 
Table 1 List of 40 surveyed works

\begin{tabular}{|c|c|c|c|}
\hline & Work & Author & Year \\
\hline 1 & Codeform (McCormack, 2012) & Jon McCormack & 2012 \\
\hline 2 & Swarm-art (Al-Rifaie \& Bishop, 2013) & $\begin{array}{l}\text { Mohammad Majid } \\
\text { et al. }\end{array}$ & $\begin{array}{l}2012- \\
2013\end{array}$ \\
\hline 3 & Untitled (Bornhofen et al., 2012) & Stefan Bornhofen et al. & 2012 \\
\hline 4 & $\begin{array}{l}\text { Where is Lourenço Marques? (Antunes, 2012; Antunes } \\
\text { \& Leymarie, 2013) }\end{array}$ & Antunes and Leymarie & $\begin{array}{l}2012- \\
2013\end{array}$ \\
\hline 5 & Time of doubles (Ji, 2012; Wakefield, 2012) & Ji and Wakefield & 2012 \\
\hline 6 & Pandemic (Dorin, 2012) & Alan Dorin & 2012 \\
\hline 7 & $\begin{array}{l}\text { Vishnu's Dance of Life and Death (Antunes \& } \\
\text { Leymarie, 2012) }\end{array}$ & $\begin{array}{l}\text { Antunes and Fol } \\
\text { Leymarie }\end{array}$ & 2011 \\
\hline 8 & EvoEco (Kowaliw, McCormack, \& Dorin, 2011) & Kowalik et al. & 2011 \\
\hline 9 & Cycles (Bisig \& Unemi, 2010) & Bisig and Unemi & 2010 \\
\hline 10 & Senhora da Graça (Antunes \& Leymarie, 2010) & $\begin{array}{l}\text { Antunes and Fol } \\
\text { Leymarie }\end{array}$ & 2010 \\
\hline 11 & Sonic Ecosystem (Bown \& McCormack, 2010) & $\begin{array}{l}\text { Bown and } \\
\text { McCormack }\end{array}$ & 2009 \\
\hline 12 & Constellation (Dorin, 2009a) & Alan Dorin & 2009 \\
\hline 13 & Habitat (Dorin, 2009b) & Dorin & 2009 \\
\hline 14 & $\begin{array}{l}\text { Untitled experiment (Niches) (McCormack \& Bown, } \\
\text { 2009) }\end{array}$ & $\begin{array}{l}\text { McCormack and } \\
\text { Bown }\end{array}$ & 2009 \\
\hline 15 & Fluid space (Ji, 2012; Ji \& Wakefield, 2012) & Ji and Wakefield & 2009 \\
\hline 16 & Quorum Sensing (Chen \& Hoyami, 2007) & Chen and Hoyami & 2008 \\
\hline 17 & Filterscape (Eldridge \& Dorin, 2009) & Eldridge et al. & 2008 \\
\hline 18 & Infinite game Ji (2012); Ji and Wakefield (2012) & Ji and Wakefield & 2008 \\
\hline 19 & $\begin{array}{l}\text { Colour cycling (Eldridge, Dorin, \& McCormack, } \\
\text { 2008) }\end{array}$ & Eldridge et al. & 2008 \\
\hline 20 & xTNZ (Antunes \& Leymarie, 2008) & $\begin{array}{l}\text { Antunes and Fol } \\
\text { Leymarie }\end{array}$ & 2006 \\
\hline 21 & Funky forest (Watson \& Gobeille, 2007) & Watson and Gobeille & 2007 \\
\hline 22 & E-volver (Driessens and Verstappen, 2006) & $\begin{array}{l}\text { Driessens and } \\
\text { Verstappen }\end{array}$ & 2006 \\
\hline 23 & Plague (Dorin, 2006) & Alan Dorin & 2006 \\
\hline 24 & Ambient Light (Spinster, 2007) & Annie Spinster & 2006 \\
\hline 25 & Lifedrop (Heudin, 2012) & Jean-Claude Heudin & 2004 \\
\hline 26 & Meniscus (Dorin, 2003) & Alan Dorin & 2003 \\
\hline 27 & Black Sholes (Demos, 2012; Portway et al., 2004) & $\begin{array}{l}\text { Autogena, Portway } \\
\text { and Hoiles }\end{array}$ & 2001 \\
\hline 28 & Eden (McCormack, 2001) & Jon McCormack & 2001 \\
\hline 29 & $\begin{array}{l}\text { Biotica (Brown, Aleksander, MacKenzie, \& Faith, } \\
\text { 2001) }\end{array}$ & Richard Brown & 2001 \\
\hline 30 & Living melodies (Dahlstedt \& Nordahl, 2001) & Dahlstedt and Nordahl & 2001 \\
\hline 31 & Listening skies (Berry et al., 2001) & Berry et al. & 2001 \\
\hline 32 & $\begin{array}{l}\text { Iki Iki (Sommerer, Mignonneau, Lopez-Gulliver, \& } \\
\text { Satomi, 2001) }\end{array}$ & Sommerer et al. & 2001 \\
\hline
\end{tabular}


Table 1 (continued)

\begin{tabular}{l|l|l|l}
\hline & Work & Author & Year \\
\hline 33 & Life Spacies (Sommerer \& Mignonneau, 2000) & $\begin{array}{l}\text { Sommerer and } \\
\text { Mignonneau }\end{array}$ & 2000 \\
\hline 34 & Garden of Chances (Hutzler et al., 2000) & Hutzler at al. & 2000 \\
\hline 35 & Relazioni Emergenti (Annunziato \& Pierucci, 2000) & $\begin{array}{l}\text { Annunziato and } \\
\text { Pierucci }\end{array}$ & 2000 \\
\hline 36 & Nagual experiment (Annunziato, 1998) & Mauro Annunziato & 1998 \\
\hline 37 & $\begin{array}{l}\text { NerveGarden (Damer, Marcelo, Revi, Furmanski, \& } \\
\text { Laurel, 2005) }\end{array}$ & Damer et al. & 1998 \\
\hline 38 & Technosphere (Prophet, 1996) & $\begin{array}{l}\text { Jane Prophet and } \\
\text { Gordon Selley }\end{array}$ & 1996 \\
\hline 39 & EIDEA (Mitchell \& Lovell, 1995) & Mitchell and Lovell & 1995 \\
\hline 40 & A-volve (Sommerer \& Mignonneau, 1994) & $\begin{array}{l}\text { Sommerer and } \\
\text { Mignonneau }\end{array}$ & 1994 \\
\hline
\end{tabular}

\subsubsection{Contextual Variables}

Context This refers to the main context of the work, to its function. Does the artwork tell or narrate, inform or document, does it visualize, sonify, monitor, mediate, transform, collect or store an event, process or story?

Referentiality Many works in EvoArt are self-referential or reflect upon life; however, a significant number also reflect about societal, political, economic or environmental processes.

Autonomy This variable describes the focus of the work in terms of input. Is the work independent from external influences (autonomous) or does it need external sources of input like the meteorological information required by EIDEA (Mitchell $\&$ Lovell, 1995) (data-driven), or user-input designing and adding new creatures. Accepted values are: autonomous, data-driven, or user.

\subsubsection{User Experience (Interactivity)}

We consider now variables describing levels and types of interactivity of a CE.

Perspective This binary parameter identifies the level of commitment of the audience with respect to the emergence of the work's outcome or storyline. When the audience plays a direct role in the narrative the work is considered personal, and impersonal otherwise.

User Functions Members of the audience may observe, explore, activate, control, select, navigate, participate, or leave traces. These interactions are classified as one of three possibilities: interpretative (observe), explorative (explore, navigate, select) or configurative (activate, control, leave trace, participate). 
Linking This variable denotes the existence of devices and processes that make a $\mathrm{CE}$ reactive to interactions with the audience. Accepted values are: none, explicit, or implicit. Explicit stands for works where there is a direct involvement of the user, usually via a haptic device such as a mouse, touch screen, tablet or pod. Implicit is when the body or its physical presence in space is captured with the help of non-interfering devices such as infra-red cameras.

Modes Modalities of perception engaging the user are captured by this variable, including the: visual, haptic, aural, movement and procedural modes. Movement may include subtle dynamic events such as finger gestures or eye gaze. Procedural refers to the cognitive dimension of the experience, where in contrast to the other modes, a rational understanding of the processes involved in the construction of the work is implied. For example, Technosphere (Prophet, 1996) builds on the illusion of an "out-there" abstracting the processes involved in its construction, whereas in works such as Cycles (Bisig \& Unemi, 2010) this procedural dimension beyond what is seen is emphasized by means of a more abstract form of representation using lines and simple geometric forms in an aesthetic popularized by computer screensavers which enhances (makes explicit) the presence of the medium and its processes. Modalities of smell and taste could potentially be included here, but this is unnecessary in our study as, to the best of our knowledge, no recent work explores such territories.

Determinability This binary indicator specifies if different interactions from the audience with the same artefact may result in similar experiences or not. This variable is subordinate to the user-function, as unique experiences exist in the explorative and dynamic modes. Accepted values are yes or no. Given the subjectivity involved in accessing what are "similar" experiences, we opted to just classify as determinable those works presented in still format, as "drawings" as McCormack puts it (McCormack \& Bown, 2009).

Access We assume the whole of the artefact is available at all times (e.g. during an exhibit period), but its access can be controlled or random. A controlled situation is illustrated for example by Listening Skies (Berry et al., 2001) where the user creates a "listener" from which point of view the world will be perceived, or by Meniscus (Dorin, 2003) where the user changes the water level, thus conditioning and controlling the outcomes. A random situation is illustrated by xTNZ (Antunes \& Leymarie, 2008) where the whole of the virtual environment can be explored in an unconstrained fashion.

Class This variable is used to indicate the computational class of the work: (1) producing static non-transient outputs; (2) producing static transient outputs; (3) exhibiting complex behaviours. An example of a static non-transient output is a static image. A static transient output defines works that keep changing over time but not in a structural way. Works with complex behaviours are locally structured, partially predictable, and will exhibit random behaviour changes in surprising and unexpected ways. 


\subsubsection{Formal Variables}

The final set of variables is used to describe the formal properties of the artefacts and how they are presented in public.

Format This describes the physical manifestation of the artefact including what format was chosen to present a CE to the public. The "format" can take one of six meanings: (i) installation denotes works designed to transform the perception of space by surrounding (embedding) the user; (ii) sculpture denotes objects that are observed as a self-contained arrangements of forms; (iii) video and (iv) interactivevideo stand for works where the artefact is presented in a minimalistic technical form with the help of a projector-note however that given the nature of CEs the term video refers here to content that is produced in real-time; (v) software-application works are experienced in the intimacy of the computer; (vi) still-imagery stands for printed works of digital photography.

Composition The second formal variable describes the mode of representation used in the composition, depending if visuals and/or sounds explicitly stand for some external entity and if the work is a collection of representational elements or is abstract.

Visual Form This descriptor is used to indicate how individuals are represented visually in the ecosystem. To cover the wide range of approaches, this category accepts a graded scale of values. Individuals can be represented by dots, lines, surfaces, volumes or ephemeral/translucent forms.

Depth This binary parameter is complementary to the visual form and indicates the presence of foreshortening in the representation. Two values are accepted to denote bi-dimensional $(2 D$ or flat $)$ or three-dimensional $(3 D$ or volumetric) representations.

Colour Works may be monochromatic or multi-coloured. Monochromatic works are few, and include black and white as well as grey-level pieces.

SFX Special effects (SFX) indicates the level of graphical sophistication, such as surface details, texture mixing, or the use of smooth elementary units and solid objects versus complex ones. Accepted values are yes or no (i.e. complex or simple).

Sonification There are multiple alternatives for the use of sound. The main dichotomy is between pre-recorded and synthesized (in real-time) sounds. A sonification effect can be composed of preselected elements, which might be played for instance as screams by individuals. Alternatively, sounds produced may be granular, i.e. synthesized and played simultaneously by different units of a CE, which is typical of swarming and particle-based approaches.

Display The CE is ultimately a system running on a computer. This (almost always) requires a visualisation. The technology used to present the $\mathrm{CE}$ to the 
public is captured by this descriptor: frontal-, vertical-, retro-, or multiple-projection, computer-screen, touch-screen or mixed-reality.

Scale This variable describes the size relationship of the individuals from the virtual population with respect to the human body. Accepted values are: micro for small sizes (typically less than $0.1 \mathrm{~m}$ ), human for sizes similar to the human body and parts (up to $3 \mathrm{~m}$ ); and macro for other larger sizes (e.g. at architectural/ urban scales).

\subsubsection{Summary}

We have presented a set of variables based on the taxonomy introduced by Carvalhais to classify generative artworks (Carvalhais, 2010). Some of the original categories were removed-i.e. Dynamics and Transiency-since they are redundant in the context of CEs. Some others had their name changed to better clarify their relation to CEs: Individual was changed to Visual Form, Sound to Sonification, Blending to SFX, shape to surfaces, transparencies to ephemeral. The nineteen selected variables are as follows:

1-Context (narrate, inform, visualize, sonify, monitor, mediate, transform, collect, store); 2-Referentiality (life, societal, political, economic, environmental); 3 Autonomy (autonomous, data-driven, user); 4-Perspective (personal, impersonal); 5-User Functions (interpretative, explorative, configurative); 6-Linking (none, explicit, conditional); 7-Modes (visual, haptic, aural, movement, procedural); 8Determinability (yes or no); 9-Access (random, controlled); 10-Class (1 (static non-transient), 2 (static transient), 3 (complex)); 11-Format (installation, sculpture, video, interactive-video, sw-app (software-application), still (imagery)); 12-Composition (representational, abstract); 13-Visual Form (dots, lines, surfaces, volumes, ephemeral); 14-Depth (2D, 3D); 15-Colour (mono (chrome), multi (coloured)); 16-SFX (yes (complex), no (simple)); 17-Sonification (pre-selected, granular); 18-Display (frontal (projection), retro (projection), multi(projection), (computer-) screen, or touch); 19- Scale (micro, human, macro).

\section{Results and Characterization}

The following tables show the classification for the three main variable types: Contextual, Interactivity, Formal. These tables were produced from a close inspection of: project websites, papers describing the implementations, and other material when available (e.g. blogs, reviews). A rapid look at the tables shows a great heterogeneity of agendas and outcomes. We discuss below the content of each table in turn. Note that WisLM (Antunes, 2012; Antunes \& Leymarie, 2013) and Technosphere (Prophet, 1996) appear twice in each table as they have been exhibited both (a) in galleries and (b) on the internet; also, Fluid space is a later 
and enhanced version of Infinite Game ( $\mathrm{Ji}, 2012)$, and similarly with Pandemic (Dorin, 2012) in relation to Plague (Dorin, 2006); note also that tables are organised by date of publication, from most to least recent.

\subsection{Contextual Variables}

First, we consider the contextual aspects of the 40 projects surveyed as listed in Table 2.

Summations of variable values are illustrated in Fig. 6.

The first aspect that emerges from the diagrammatic summary (Fig. 6) is that CEs operate autonomously within an aesthetic that is largely focused around visualizations of processes of life. A close inspection of Table 2 reveals that the internal dynamics of the processes of life, such as the spread of diseases in Pandemic (Dorin, 2012) or niche-formation in Relazioni Emergenti (Annunziato \& Pierucci, 2000), and self-referentiality, such as the abstract compositions resulting from processes of natural selection in Galatema (Lioret, 2012), dominate largely representing nearly $70 \%$ of the referentiality spectrum. Together, environmental, societal, political and the economy are themes which represent only about a third of the spectrum. This should not be too surprising if we take into consideration the historical agenda of ALife which has often been used in science to demonstrate biological phenomena and offer suggestions on how such phenomena may arise and function. CEs in particular have been used to draw conclusions about complex adaptive systems. As Whitelaw underlines: ALife art is engaged in the pursuit of an agenda where visualizing and emphasizing life and its processes is a top priority (Whitelaw, 2004). This situation indicates potential avenues to explore in the future by artists wanting to demarcate themselves from the main themes of previous works.

Looking into the specifics of projects from the point of view of the Context variable, it is not too surprising to find that most works operate in the visual realm (95\%), and almost half of them make use of the aural dimension (45\%). More recent works tend to explore the two modalities integrated together. The other main common denominator is the exploration of interactions with the audience.

Only a small minority or works require external data as input (7\%), but, by contrast, the majority requires the audience to be active and perform actions directly impacting the CE (60\%). Some works are entirely dependent on such actions: for instance, Cycles (Bisig \& Unemi, 2010) requires the user to put their hand under the device containing the camera in order to let the virtual agents feed themselves. In other works however the user only interferes with the natural evolution of the CE, such as in A-Volve (Sommerer \& Mignonneau, 1994), where the audience may insert a new fish in the pool, thus changing the status quo of the virtual tank. The following section analyses the interactive aspect in more detail. 
Table 2 Contextual classification of the 40 surveyed works

\begin{tabular}{|c|c|c|c|}
\hline Work & Context & Referentiality & Autonomy \\
\hline Codeform (McCormack, 2012) & Vis + sonify & Societal & User \\
\hline Swarm-art (Al-Rifaie \& Bishop, 2013) & Vis + sonify & Life & User \\
\hline Untitled (Bornhofen et al., 2012) & Visualize & Life & Autonomous \\
\hline $\begin{array}{l}\text { WisLM (a) (Antunes, 2012; Antunes \& } \\
\text { Leymarie, 2013) }\end{array}$ & Vis + mediate & Political & Autonomous \\
\hline $\begin{array}{l}\text { WisLM (b) (Antunes, 2012; Antunes \& } \\
\text { Leymarie, 2013) }\end{array}$ & Vis + mediate & Political & Autonomous \\
\hline Time of doubles (Ji, 2012; Wakefield, 2012) & Vis + sonify & Life & User \\
\hline Pandemic (Dorin, 2012) & Vis + sonify & Life & User \\
\hline Vishnu's (Antunes \& Leymarie, 2012) & Visualize & Societal & Autonomous \\
\hline EvoEco (Kowaliw et al., 2011) & Visualize & Life & User \\
\hline Cycles (Bisig \& Unemi, 2010) & Visualize & Life & User \\
\hline SraGraca (Antunes \& Leymarie, 2010) & Visualize & Environmental & Autonomous \\
\hline Constellation (Dorin, 2009a) & Visualize & Life & Autonomous \\
\hline Habitat (Dorin, 2009a) & Vis + sonify & Life & Autonomous \\
\hline Niches (McCormack \& Bown, 2009) & Visualize & Life & Autonomous \\
\hline $\begin{array}{l}\text { Sonic Ecosystem (Bown \& McCormack, } \\
\text { 2010) }\end{array}$ & Vis + sonify & Life & Autonomous \\
\hline Fluid space (Ji, 2012) & Vis + sonify & Life & User \\
\hline Quorum Sensing (Chen \& Hoyami, 2007) & Vis + sonify & Life & User \\
\hline Filterscape (Eldridge \& Dorin, 2009) & Sonify & Life & Autonomous \\
\hline Infinite game (Ji, 2012) & Vis + sonify & Life & User \\
\hline Colour cycling (Eldridge et al., 2008) & Visualize & Life & Autonomous \\
\hline Funky forest (Watson \& Gobeille, 2007) & Vis + sonify & Environmental & User \\
\hline xTNZ (Antunes \& Leymarie, 2008) & Vis + sonify & Societal & User \\
\hline E-volver (Driessens and Verstappen, 2006) & Visualize & Life & User \\
\hline Plague (Dorin, 2006) & Vis + sonify & Life & User \\
\hline Ambient light (Spinster, 2007) & Visualize & Life & User \\
\hline Lifedrop (Heudin, 2012) & Visualize & Life & Autonomous \\
\hline Meniscus (Dorin, 2003) & Vis + sonify & Life & User \\
\hline $\begin{array}{l}\text { Black sholes (Demos, 2012; Portway et al., } \\
\text { 2004) }\end{array}$ & Visualize & Economic & Data-driven \\
\hline Eden (McCormack, 2001) & Vis + sonify & Life & User \\
\hline Biotica (Brown et al., 2001) & Vis + sonify & Life & User \\
\hline $\begin{array}{l}\text { Living Melodies (Dahlstedt \& Nordahl, } \\
\text { 2001) }\end{array}$ & Sonify & Life & Autonomous \\
\hline Listening skies (Berry et al., 2001) & Vis + sonify & Life & User \\
\hline Iki Iki (Sommerer et al., 2001) & Visualize & Life & User \\
\hline $\begin{array}{l}\text { Life spacies (Sommerer \& Mignonneau, } \\
\text { 2000) }\end{array}$ & Visualize & Societal & User \\
\hline Garden of Chances (Hutzler et al., 2000) & $\begin{array}{l}\text { Vis }+ \text { son } \\
+ \text { monitor }\end{array}$ & Environmental & Data-driven \\
\hline NerveGarden (Damer et al., 2005) & Visualize & Life & User \\
\hline
\end{tabular}


Table 2 (continued)

\begin{tabular}{l|l|l|l}
\hline Work & Context & Referentiality & Autonomy \\
\hline Nagual experiment (Annunziato, 1998) & Visualize & Life & Autonomous \\
\hline $\begin{array}{l}\text { Relazioni Emergenti (Annunziato \& } \\
\text { Pierucci, 2000) }\end{array}$ & Vis + sonify & Life & User \\
\hline Technosphere (a) (Prophet, 1996) & Visualize & Societal & User \\
\hline Technosphere (b) Prophet (1996) & Visualize & Societal & User \\
\hline EIDEA (Mitchell \& Lovell, 1995) & $\begin{array}{l}\text { Vis + son } \\
+ \text { monitor }\end{array}$ & Environmental & Data-driven \\
\hline A-volve (Sommerer \& Mignonneau, 1994) & Visualize & Life & User \\
\hline
\end{tabular}

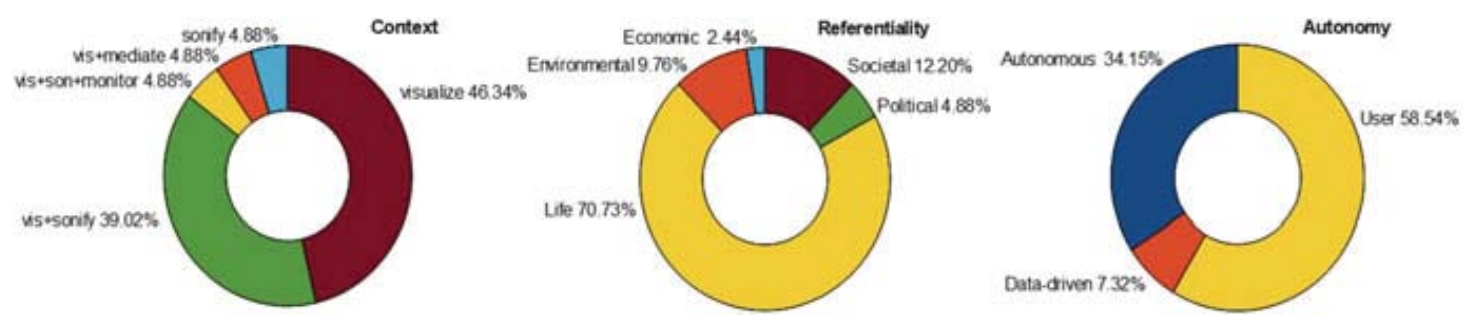

Fig. 6 Diagrammatic summary of the context of the works

\subsection{Interactivity}

Table 3 and Fig. 7 capture and summarise the interactivity of the 40 works.

With no exception all the works under scrutiny produce either a visual or audio outcome to be experienced and appreciated. This naturally results from the selection criteria used, which required works to be artistic or exhibited in public. The audience is an integral part of most works and the interactive devices are explicit and visible for the large part (45\%). In $22 \%$ of the instances however, the body presence is captured without the help of any accessory haptic devices, usually by means of computer vision techniques. This percentage would have substantially risen if we had considered only interactive works. Also, note that in the near future, the new possibilities provided by interactive technologies such as Microsoft's Kinect and its descendants are likely to have a major impact on the field (i.e. raise the influence of body movement and gesture-based interactions).

The explorative component is present in $38 \%$ of the works, but only a rather small number of projects $(25 \%)$ let the user configure the settings (or interfere with the evolution). Meniscus (Dorin, 2003) provides an example where the audience controls the level of virtual water in the simulation. This small percentage of works allowing configurative tasks is rather surprising, in particular since we have considered the actions of adding or removing members of the population (of the $\mathrm{CE}$ ) as part of this category. As mentioned earlier one conclusion to derive from our study is the untapped potential for greater levels of interactivity, in particular for the exploration of the configurative roles played by the audience.

We further underline that although a $\mathrm{CE}$ is in essence a complex system often exhibiting non-determinable outcomes, it remains constrained by parameters 
Table 3 The user (interactivity) functions of the 40 surveyed works

\begin{tabular}{|c|c|c|c|c|c|c|c|}
\hline Work & Perspect. & User & Link & Mode & Det. & Acces. & Class \\
\hline $\begin{array}{l}\text { Codeform } \\
\text { (McCormack, } \\
\text { 2012) }\end{array}$ & Personal & Configurative & Implicit & 3 & No & Random & 2 \\
\hline $\begin{array}{l}\text { Swarm-art } \\
\text { (Al-Rifaie \& } \\
\text { Bishop, 2013) }\end{array}$ & Personal & Configurative & Explicit & 2 & No & Random & 2 \\
\hline $\begin{array}{l}\text { Untitled } \\
\text { (Bornhofen et al., } \\
\text { 2012) }\end{array}$ & Impersonal & Interpretative & None & 1 & Yes & Controlled & 1 \\
\hline $\begin{array}{l}\text { WisLM } \\
\text { (a) (Antunes \& } \\
\text { Leymarie, 2013) }\end{array}$ & Impersonal & Explorative & Explicit & 3 & No & Random & 2 \\
\hline $\begin{array}{l}\text { WisLM } \\
\text { (b) (Antunes \& } \\
\text { Leymarie, 2013) }\end{array}$ & Impersonal & Explorative & Explicit & 3 & No & Random & 2 \\
\hline $\begin{array}{l}\text { Time of Doubles } \\
\text { (Ji, 2012; Wake- } \\
\text { field, 2012) }\end{array}$ & Personal & Explorative & Implicit & 5 & No & Random & 3 \\
\hline $\begin{array}{l}\text { Pandemic (Dorin, } \\
\text { 2012) }\end{array}$ & Personal & Interpretative & Implicit & 4 & No & Random & 2 \\
\hline $\begin{array}{l}\text { Vishnu's } \\
\text { (Antunes \& } \\
\text { Leymarie, 2012) }\end{array}$ & Impersonal & Interpretative & None & 2 & No & Random & 2 \\
\hline $\begin{array}{l}\text { EvoEco } \\
\text { (Kowaliw et al., } \\
\text { 2011) }\end{array}$ & Personal & Explorative & Explicit & 3 & No & Controlled & 1 \\
\hline $\begin{array}{l}\text { Cycles (Bisig \& } \\
\text { Unemi, 2010) }\end{array}$ & Personal & Interpretative & Explicit & 3 & No & Random & 3 \\
\hline $\begin{array}{l}\text { Sra Graca } \\
\text { (Antunes \& } \\
\text { Leymarie, 2010) }\end{array}$ & Impersonal & Interpretative & Explicit & 4 & No & Random & 2 \\
\hline $\begin{array}{l}\text { Constellation } \\
\text { (Dorin, 2009a) }\end{array}$ & Impersonal & Interpretative & None & 3 & No & Random & 2 \\
\hline $\begin{array}{l}\text { Habitat (Dorin, } \\
\text { 2009a) }\end{array}$ & Impersonal & Interpretative & None & 3 & No & Random & 2 \\
\hline $\begin{array}{l}\text { Niches (McCor- } \\
\text { mack \& Bown, } \\
\text { 2009) }\end{array}$ & Impersonal & Interpretative & None & 2 & Yes & Controlled & 1 \\
\hline $\begin{array}{l}\text { Sonic Ecosystem } \\
\text { (Bown \& } \\
\text { McCormack, } \\
\text { 2010) }\end{array}$ & Impersonal & Interpretative & None & 2 & No & Random & 2 \\
\hline $\begin{array}{l}\text { Fluid space (Ji, } \\
\text { 2012) }\end{array}$ & Personal & Explorative & Explicit & 5 & No & Random & 3 \\
\hline $\begin{array}{l}\text { Quorum Sens. } \\
\text { (Chen \& } \\
\text { Hoyami, 2007) }\end{array}$ & Personal & Explorative & Implicit & 4 & No & Random & 3 \\
\hline
\end{tabular}


Table 3 (continued)

\begin{tabular}{|c|c|c|c|c|c|c|c|}
\hline Work & Perspect. & User & Link & Mode & Det. & Acces. & Class \\
\hline $\begin{array}{l}\text { Filterscape } \\
\text { (Eldridge \& } \\
\text { Dorin, 2009) }\end{array}$ & Impersonal & Interpretative & None & 2 & No & Random & 2 \\
\hline $\begin{array}{l}\text { Infinite game (Ji, } \\
\text { 2012) }\end{array}$ & Personal & Explorative & Explicit & 5 & No & Random & 3 \\
\hline $\begin{array}{l}\text { Colour cycling } \\
\text { (Eldridge et al., } \\
\text { 2008) }\end{array}$ & Impersonal & Interpretative & None & 2 & No & Random & 1 \\
\hline $\begin{array}{l}\text { Funky Forest } \\
\text { (Watson \& } \\
\text { Gobeille, 2007) }\end{array}$ & Personal & Explorative & Implicit & 5 & No & Random & 3 \\
\hline $\begin{array}{l}\text { xTNZ (Antunes } \\
\text { \& Leymarie, } \\
\text { 2008) }\end{array}$ & Personal & Explorative & Explicit & 3 & No & Random & 2 \\
\hline $\begin{array}{l}\text { E-volver } \\
\text { (Driessens and } \\
\text { Verstappen, } \\
\text { 2006) }\end{array}$ & Personal & Explorative & Explicit & 3 & No & Controlled & 1 \\
\hline $\begin{array}{l}\text { Plague (Dorin, } \\
\text { 2006) }\end{array}$ & Personal & Explorative & Implicit & 3 & No & Random & 2 \\
\hline $\begin{array}{l}\text { Ambient Light } \\
\text { (Spinster, 2007) }\end{array}$ & Personal & Interpretative & Explicit & 2 & No & Random & 2 \\
\hline $\begin{array}{l}\text { Lifedrop } \\
\text { (Heudin, 2012) }\end{array}$ & Impersonal & Configurative & None & 2 & No & Random & 2 \\
\hline $\begin{array}{l}\text { Meniscus (Dorin, } \\
\text { 2003) }\end{array}$ & Personal & Configurative & Explicit & 5 & No & Random & 2 \\
\hline $\begin{array}{l}\text { Black } \\
\text { Sq. (Demos, } \\
\text { 2012; Portway } \\
\text { et al., 2004) }\end{array}$ & Impersonal & Interpretative & None & 4 & No & Random & 2 \\
\hline $\begin{array}{l}\text { Eden (McCor- } \\
\text { mack, 2001) }\end{array}$ & Personal & Explorative & Implicit & 4 & No & Random & 2 \\
\hline $\begin{array}{l}\text { Biotica (Brown } \\
\text { et al., 2001) }\end{array}$ & Personal & Explorative & Explicit & 3 & No & Random & 2 \\
\hline $\begin{array}{l}\text { Living Melod. } \\
\text { (Dahlstedt \& } \\
\text { Nordahl, 2001) }\end{array}$ & Impersonal & Interpretative & None & 1 & No & Random & 2 \\
\hline $\begin{array}{l}\text { Listen. Skies } \\
\text { (Berry et al., } \\
\text { 2001) }\end{array}$ & Personal & Explorative & Explicit & 4 & No & Random & 2 \\
\hline $\begin{array}{l}\text { Iki Iki } \\
\text { (Sommerer et al., } \\
\text { 2001) }\end{array}$ & Personal & Configurative & Explicit & 3 & No & Random & 3 \\
\hline $\begin{array}{l}\text { Life spacies } \\
\text { (Sommerer \& } \\
\text { Mignonneau, } \\
\text { 2000) }\end{array}$ & Personal & Configurative & Implicit & 5 & No & Random & 2 \\
\hline
\end{tabular}


Table 3 (continued)

\begin{tabular}{l|l|l|l|l|l|l|l}
\hline Work & Perspect. & User & Link & Mode & Det. & Acces. & Class \\
\hline $\begin{array}{l}\text { Garden of } \\
\text { Ch. (Hutzler } \\
\text { et al., 2000) }\end{array}$ & Personal & Configurative & Explicit & 4 & No & Random & 2 \\
\hline $\begin{array}{l}\text { NerveGarden } \\
\text { (Damer et al., } \\
\text { 2005) }\end{array}$ & Personal & Explorative & Explicit & 2 & No & Random & 2 \\
\hline $\begin{array}{l}\text { Nagual Exp. } \\
\text { (Annunziato, } \\
\text { 1998) }\end{array}$ & Impersonal & Interpretative & None & 1 & Yes & Controlled & 1 \\
\hline $\begin{array}{l}\text { Relazioni Emer. } \\
\text { (Annunziato \& } \\
\text { Pierucci, 2000) }\end{array}$ & Personal & Configurative & Implicit & 3 & No & Random & 3 \\
\hline $\begin{array}{l}\text { Technos. } \\
\text { (a) (Prophet, } \\
\text { 1996) }\end{array}$ & Personal & Configurative & Explicit & 2 & No & Controlled & 2 \\
\hline $\begin{array}{l}\text { Technos. } \\
\text { (b) (Prophet, } \\
\text { 1996) }\end{array}$ & Personal & Configurative & Explicit & 2 & No & Controlled & 2 \\
\hline $\begin{array}{l}\text { EIDEA (Mitchell } \\
\text { \& Lovell, 1995) }\end{array}$ & Impersonal & Interpretative & None & 3 & No & Random & 3 \\
\hline $\begin{array}{l}\text { A-volve } \\
\text { (Sommerer \& } \\
\text { Mignonneau, } \\
\text { 1994) }\end{array}$ & Personal & Explorative & Explicit & 4 & No & Random & 2 \\
\hline
\end{tabular}
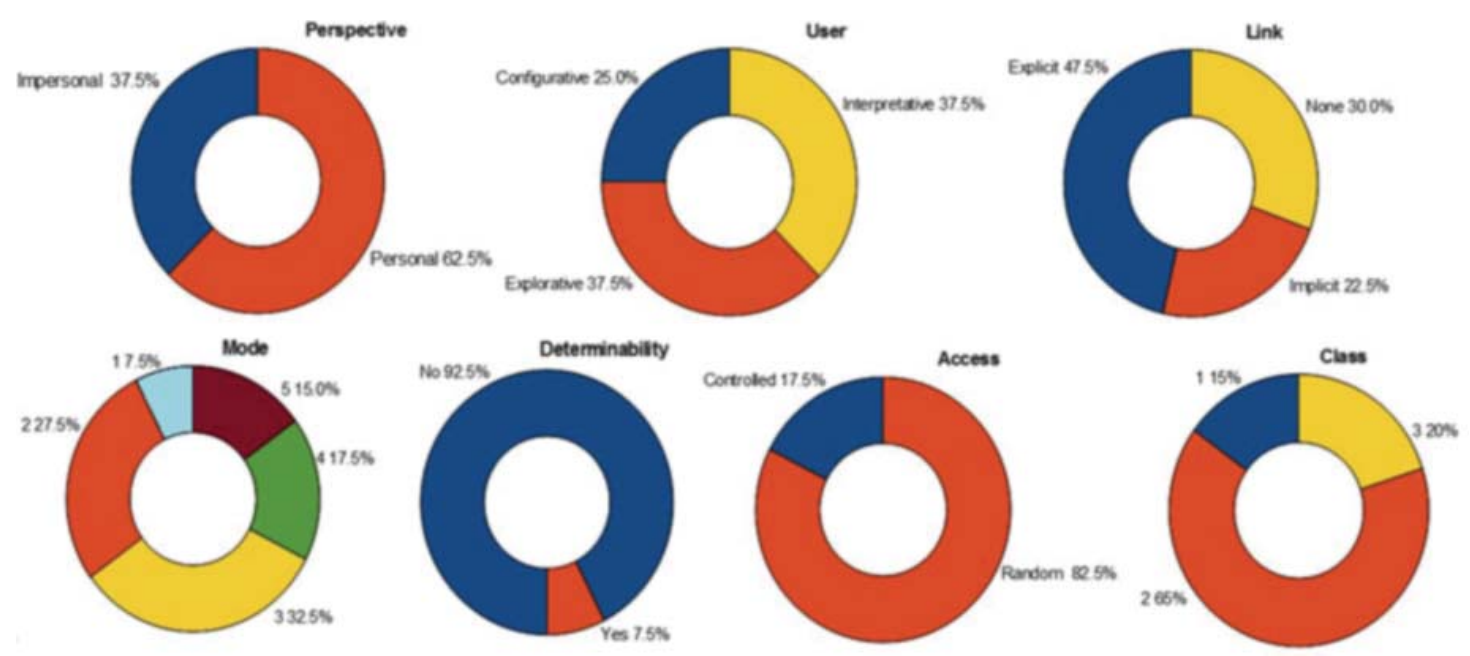

Fig. 7 Diagrammatic summary of the interactivity of the works 


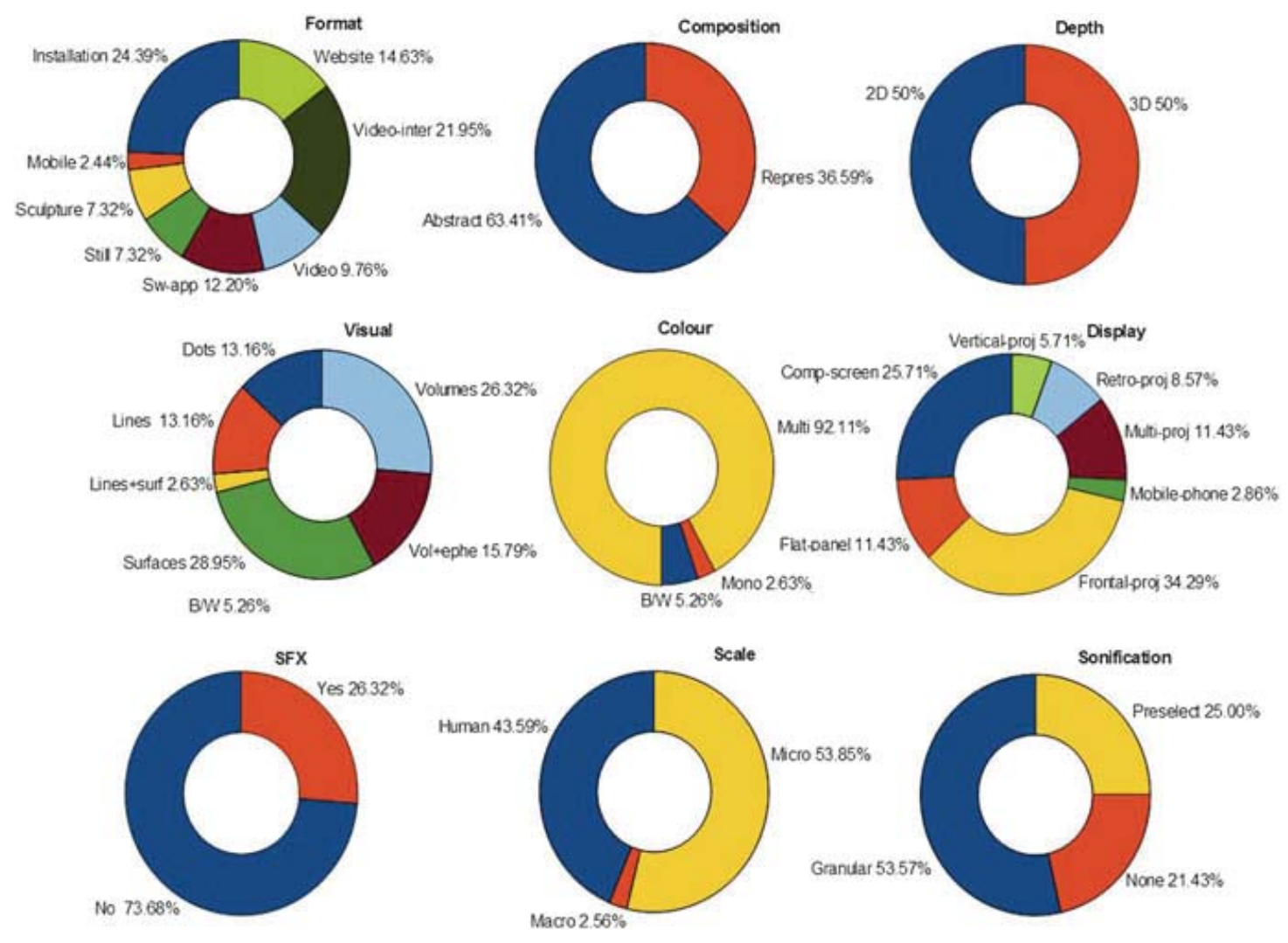

Fig. 8 Diagrammatic summary of the formal presentation

restricted to operate only within set ranges. ${ }^{1}$ For instance, if the programmer designs the system as composed by individuals represented by triangles, these will never become circles or take other geometrical forms. Having full access to non-determinability remains a "holy grail" of ALife: i.e. producing some open-ended systems which automatically generate and change their own rules of production (Mccormack, 2005).

In terms of the Linking variable, we notice that nearly half the works use explicit interaction devices such as a mouse in XTNZ, hands blocking a sensor's view in Cycles, or wearing special goggles in Biotica. For nearly another quarter of the works the presence of the user is captured in a more discrete, implicit way (22\%). In terms of the Class variable, the majority of works (65\%) keep changing over time but not in a structural way (class \#2), while a significant number exhibit more complex behaviors (class \#3 at $22 \%$ ). As for the Mode variable, about 1/3 of the works explore simultaneously four or more of the properties analysed: visual, haptic, aural, movement from the user and perception of procedural qualities. In terms of the Perspective variable, for $62 \%$ of the cases the user has a personal engagement with the story, either by creating a new creature (e.g. in AVolve (Sommerer \& Mignonneau, 1994)), or adding food/energy (e.g. in Fluid Space $(\mathrm{Ji}, 2012)$ ), or introducing a disease to the virtual world (e.g. in Pandemic (Dorin, 2012)) (Fig. 8).

\footnotetext{
${ }^{1}$ Note that most works (93\%) are not controlled; the only exceptions being works presented to the public as static pictures.
} 
Finally, the Access variable provides us with a clear pattern that distinguishes CEs from other interactive media instances such as games, as a large majority $(83 \%)$ of the works represented here do not offer "levels" or hidden areas of the world that the user can activate by means of their actions.

\subsection{Formal Parameters}

Table 4 presents the classification of the 40 works with regards to their formal variables making explicit their mode of presentation or exhibition.

The openness and plasticity of CEs is made explicit by our study. In the works analysed, while there is a similarity of methods used, this is combined with a great disparity of outcomes and heterogeneity in the Formats of production. The personal computer is not the privileged mode of operation, with only one third of the works taking the format of websites or software applications. Works exhibited in gallery spaces dominate the sample (nearly $70 \%$ ). From this large group, video projections and interactive-video clearly dominate. As a consequence, works tend to operate at human body (44\%) or smaller (micro) scales (54\%), and we notice that only one project in our sample exploits macro scales [Constellation (Dorin, 2009a)].

When it comes to the Composition, we took in consideration the representational scheme of choice composed of the shape, colour, the trace used, and the scale of the artefacts. Results suggest that there is a clear dominance of the abstract over the representational. This is not too surprising taking into consideration the agenda from ALife of "life as it could be". In terms of Visual Forms, dots and lines are rarely used in comparison to surfaces and volumes. Dots usually produce plasmalike looking works as a function of changing CE dynamics, whereas surfaces and volumes are the carriers of more traditional modes of representation, including the use of perspective and foreshortening.

As could be expected, the Color variable is dominated by multi-chromatic works over black and white or monochrome works. Surprisingly however, there is not much sophistication involved in the resulting visualizations. Authors seem to prefer solid forms rather than SFX such as blending textures or using complex graphics. This result might be somewhat biased due to the temporal scale of the particular sample under analysis, which includes a fair number of works from the 1990s and early 2000s when rendering sophisticated visuals in real time was comparatively much harder than in recent years.

When it comes to the Depth variable, there is no clear dominance of the use of $3 \mathrm{D}$ versus $2 \mathrm{D}$. This might change in the future, as $3 \mathrm{D}$ technologies (of production and display) become more accessible.

The freedom of expression of CEs is again suggested when we consider the Sonification variable. Granular and synthesized sounds are used in $54 \%$ of the works, while only $25 \%$ use pre-selected more "naturalistic" sounds. Examples of sonification include the literal translation of CE dynamics [e.g. Time of Doubles (Ji, 2012; Wakefield, 2012)], abstract formulations [e.g. Living Melodies (Dahlstedt \& 


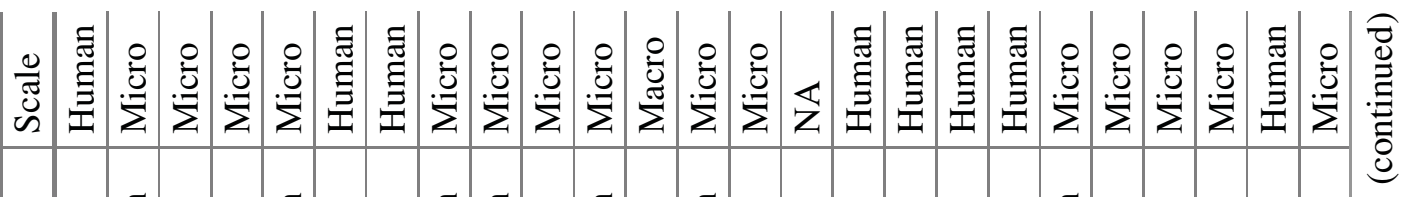

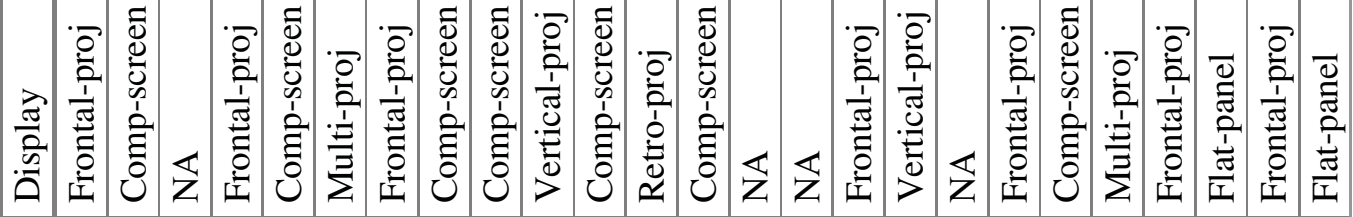

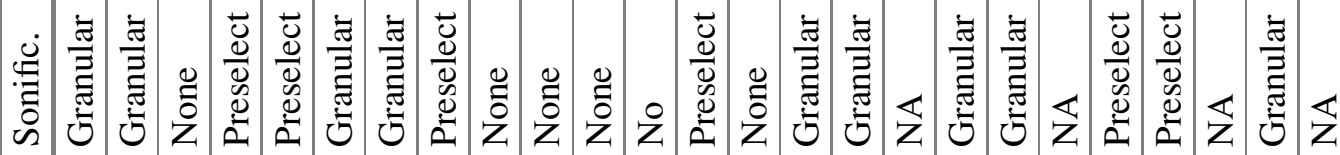

崖

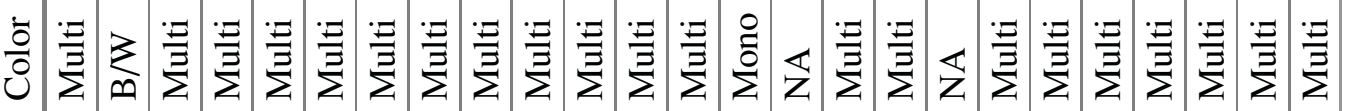

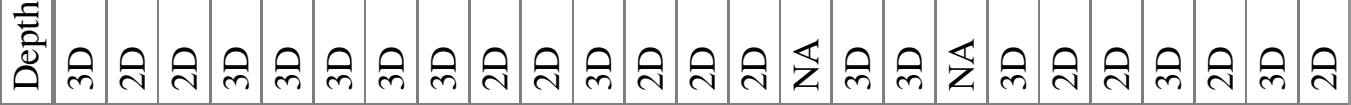

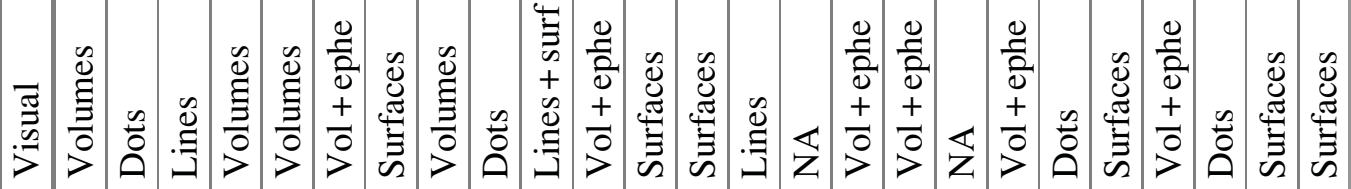

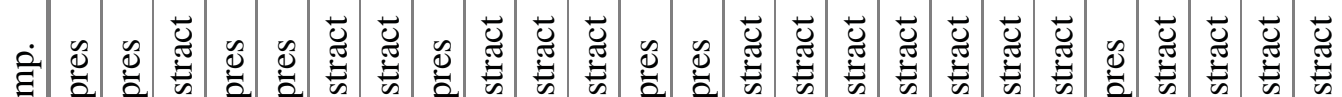

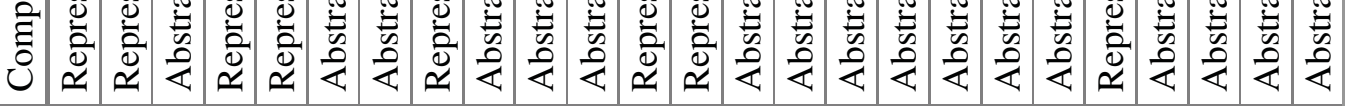

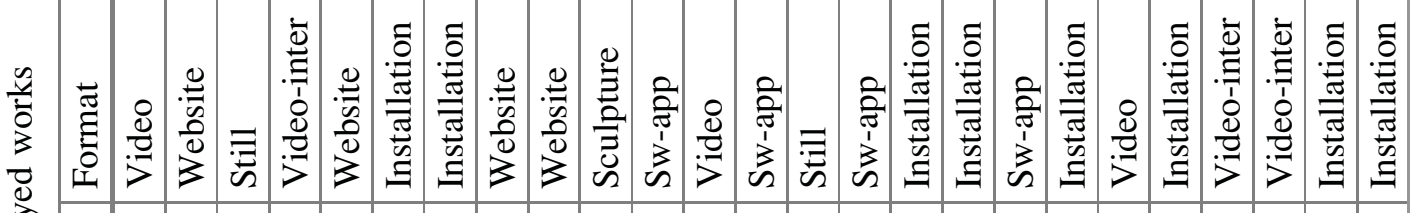

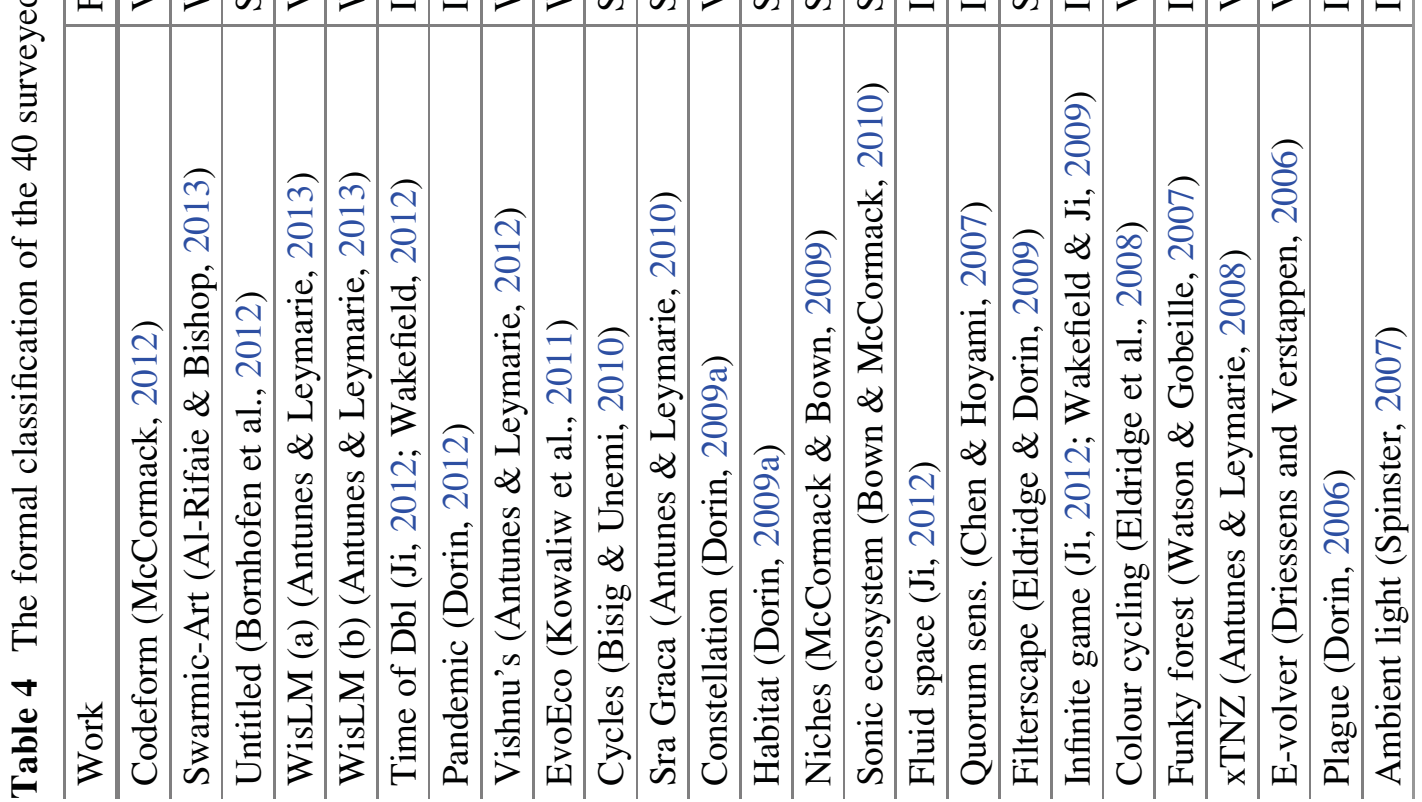




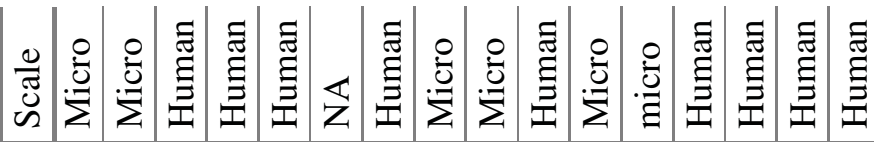

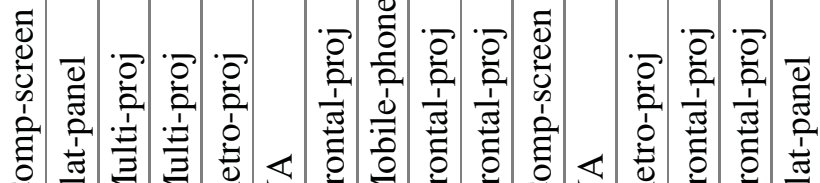

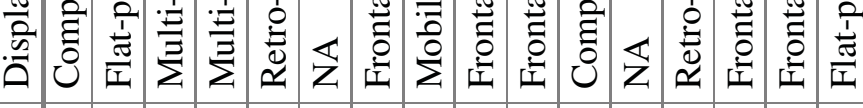

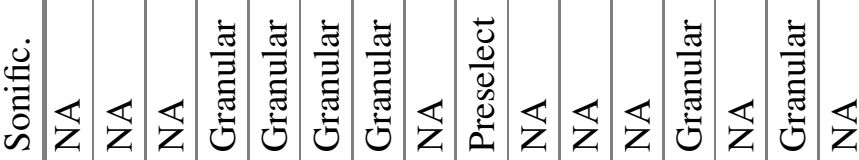
至

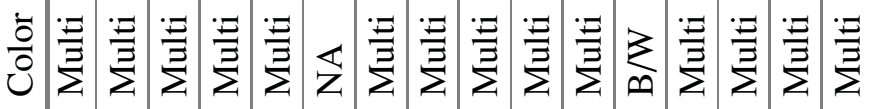

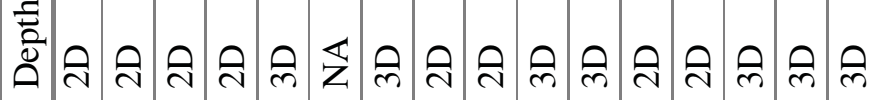

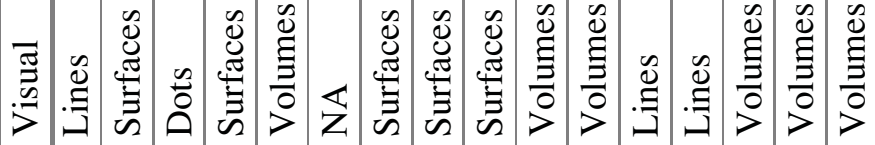

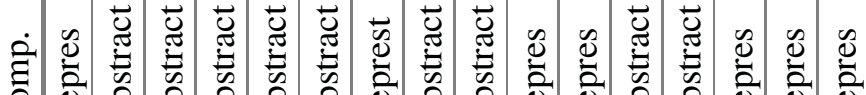

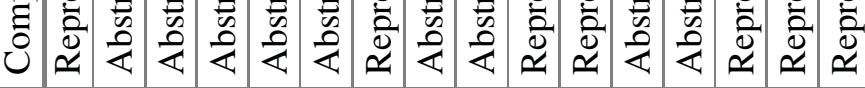

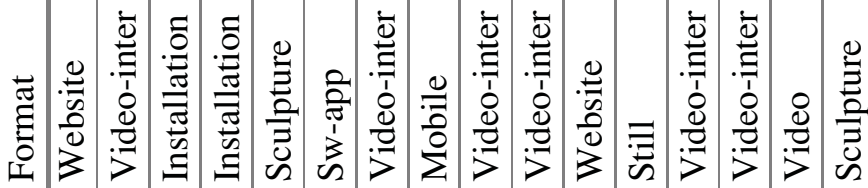

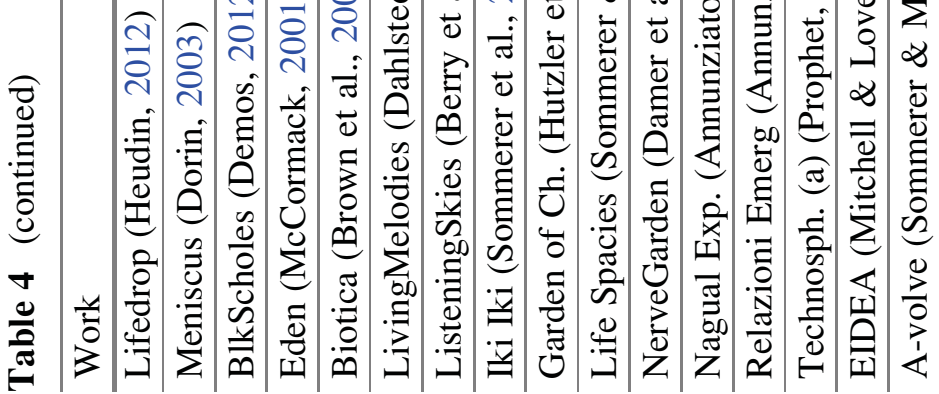


Nordahl, 2001)], or having visuals being entirely secondary while the focus of the work is on the sound generated [e.g. Filterscape (Eldridge \& Dorin, 2009)]. Surprising is the fact that there is no sonification at all in a large number of the works (22\%), as reported in associated papers, blogs or websites. It is also worth mentioning that some works use sounds independently from the CE's dynamics [such as in WisLM (Antunes, 2012; Antunes \& Leymarie, 2013) and Vishnu's (Antunes \& Leymarie, 2012)].

\section{Discussion and Future Perspectives}

Since the early 1990s artists have been experimenting with ways in which Computational Ecosystems (CEs), as a toolbox and aesthetical framework, could expand and enhance their praxis. ${ }^{2}$ The collaboration between artists and scientists within the domain of ALife has produced new art forms, new visual languages, and new ways of relating life processes to aesthetics. And as new forms emerge, artists are finding even more creative, exciting applications. These are presented in a diversity of forms: from single-channel videos screened on a gallery monitor or video installations, to the intimacy of the personal-computer. Challenging traditional ideas of art and science, these artists use the technology as moving canvases and sculptures for often surreal, sometimes self-indulgent, usually powerful art works. They expand the visual vocabulary and force viewers to think about the relationship between art and science in a new way.

\subsection{CEs as Art Forms}

The use of CEs as an art producing medium establishes a dialogue with pictorial and representational traditions. It inherits methods and canons which have been in practice for centuries and now manifest themselves in structuring new works. For instance, the canvas is slowly and patiently filled with "virtual ink" in Annunziato's works (Annunziato, 1998; Annunziato \& Pierucci, 2000). Each agent on the canvas is a virtual drawing brush which traces virtual ink until it reaches another agent at which point it stops its activity and "dies". Annunziato's methodology echoes the processes involved in traditional drawing and painting: layers of ink are added to the canvas in a material composition of juxtapositions, accumulation and masking.

\footnotetext{
${ }^{2}$ We have to keep in mind that the sample scrutinized here illustrates about two decades of practice where we have witnessed an immense technological evolution. As a consequence, works from the first decade might exhibit features that are systematically distinct from those of the second. The ability to create (or make use of) certain formal properties or interactive features might not have existed earlier and we should keep this in mind. A more in-depth analysis would be needed to clarify this point.
} 
A similar procedure is followed in Driessens and Verstappens's works where the canvas is akin a memory of spatial changes (Driessens and Verstappen, 2006). These works portrait the spatial dynamics of the community of agents working together on the canvas exhibited in a gallery space. Drawings result from changes in concentration and density in the community. However, in an interactive process visitors can destroy whole populations of agents whose drawings they do not like or care for. With the help of a touch screen, they can choose a new orientation for the work from a set of possible and logical continuations which can be initiated from the present configuration. In a process of subtraction, similar to the one when material is carved out from a marble piece to let emerge a sculpture, Driessens and Verstappen's audience removes raw possibilities from a chunk of virtual potentials to let the work progress in a possibly more likeable direction. This operative arithmetic of addition and subtraction forms the essence of the dynamics of this "vivid painting in motion" as Lioret describes it (Lioret, 2012).

Other classic representational strategies include the omnipresent duality between interior and exterior spaces. This is emphasized in the tradition of visual arts by the frame surrounding the painting or photograph, or the pedestal supporting and elevating the vase or sculpture; it echoes the classical idea that the human stands outside, in the exterior space, to observe the artefact sitting in the interior space, the focus of our attention. Most works we analysed share this dichotomy by emphasising the computational nature of the artefacts produced and the window (or screen) paradigm which is still dominant. This dichotomy is used and integrated with contextual advantage in the narratives of works such as Senhora da Graça (Antunes \& Leymarie, 2010) or EIDEA (Mitchell \& Lovell, 1995) where the interior/exterior duality is emphasised by contrasting the "natural outlooks" of an exterior space from the mechanistic intricacies of the artefact production.

However, artists making "vivid painting in motion" do not constrain their practice to established processes and methods inherited from classical art despite being greatly influenced by these. The artefacts produced owe much as well to contemporary art forms such as video and installation art. Challenging the interior/ exterior dichotomy, works such as Pandemic (Dorin, 2012), Eden (McCormack, 2001) and in general works in the format of installations try to blur the differences between the virtual and tangible spaces. These works combine a $\mathrm{CE}$ with sensing techniques, often adapted from computer vision, to capture the audience's location in a subtle way. For instance, the physical presence of the audience in Eden energizes a virtual world. The audience becomes the center of attention of the virtual creatures who sing to call their attention and attract them in order to obtain more energy. A similar approach was followed in the Artificial Nature series where the body's shape and volumetric information is captured and transformed into energetic particles in a virtual space (Wakefield \& Ji, 2009). The audience does not always play a positive role: in Pandemic for instance, the avatars of the members of the audience become a spreading disease (Dorin, 2012).

We pointed out earlier that the generative powers of a CE rely on the gradual and cumulative effects of the changes produced by the dynamics of the autonomous elementary units of the system. Time is omnipresent. This is an essential component 
for any CE's operation. It is a structuring and definite variable, and works produced using CEs are naturally affiliated with the traditions of kinetic art.

As our study demonstrates, works tend to be abstract in their appearance. Members of the virtual population are represented by dots (Driessens and Verstappen, 2006), lines (Annunziato, 1998), surface shapes (Dorin, 2006), or 3D volumes (Antunes \& Leymarie, 2010). The data illustrates the openness of the methodology and none of these forms dominates the others. In some instances we have outcomes with visuals rendered having plasma-like qualities (Driessens and Verstappen, 2006), whereas in others we have communities of 3D avatars walking in virtual worlds (Antunes, 2012; Antunes \& Leymarie, 2013). However only in a few cases does the work represent realistically the appearance of existing lifeforms. Abstraction (of form) is dominant while the motto "life-as-it-could" inherited from ALife reigns over most of the spectrum of this praxis.

Nevertheless, CEs as used in EvoArt remain representational. ALife art owes much to the tradition of "organicism" with its agenda and interest in representations of life. And while ALife art is not necessarily representational in the appearance of life forms, it remains in the way it simulates how life operates. This has been pointed out before, in particular by Mitchell Whitelaw (Whitelaw, 2004). This is indeed a fundamental aspect that is common to all the artefacts surveyed in our study. Here it might be helpful to recall Rosalind Krauss when she questions the modernist medium-specificity in the arts. She argues the medium is not reducible as the "specific material support for a traditional aesthetic genre" (Krauss, 2011). This expanded notion of the medium that she is proposing, detached from the technical substratum, is rather grounded on a set of historically situated praxis, or what she calls the "technical support". ${ }^{3}$ EvoArt provides examples of an artistic praxis where it is not mainly the technological medium that constitutes or defines the aesthetics: it is the ideas implemented that are important rather than the means of implementing them. The technical support of EvoArt is the set of ideas and methods informing this particular artistic praxis, including artificial life, cyberculture, systems theory, cybernetics, and the $\mathrm{CE}$ as a generative technique. The generative technology remains open and may be used for the purpose of varied artistic agendas as confirmed by our survey.

\footnotetext{
${ }^{3}$ The purist modernist tradition dwells much around the medium, of playing with the properties of the medium. Consider painting: a modernist will ask what can be done with painting, how far can we take it, use its material constraints; and then follows the questioning of what are the "materials of painting". Krauss contests that idea and argues that it is the "technical support" one should consider, which is not strictly rooted in the properties of the medium, but rather on the set of ideas that inform the practice. For example, the painter might still be working with canvas and ink, but the work is subordinated to an idea, a subject and this is what becomes central. So for instance Ed Rusha is working with the subculture of Los Angeles, the automobile, its slang, the movie-stars (Krauss, 2011).
} 
(a)

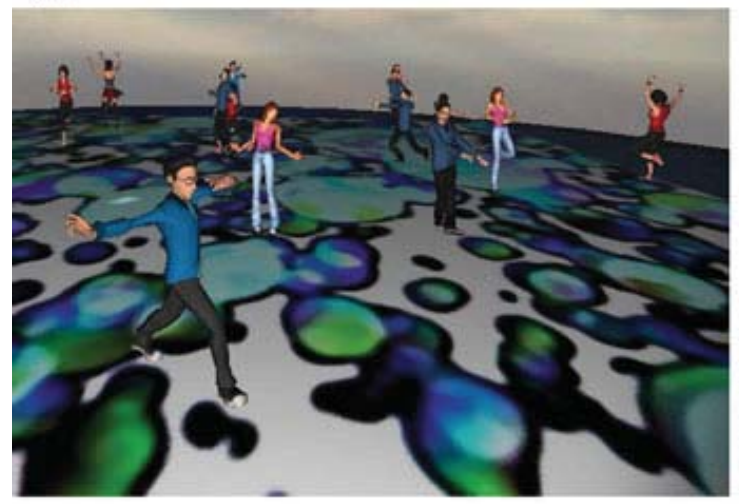

(c)

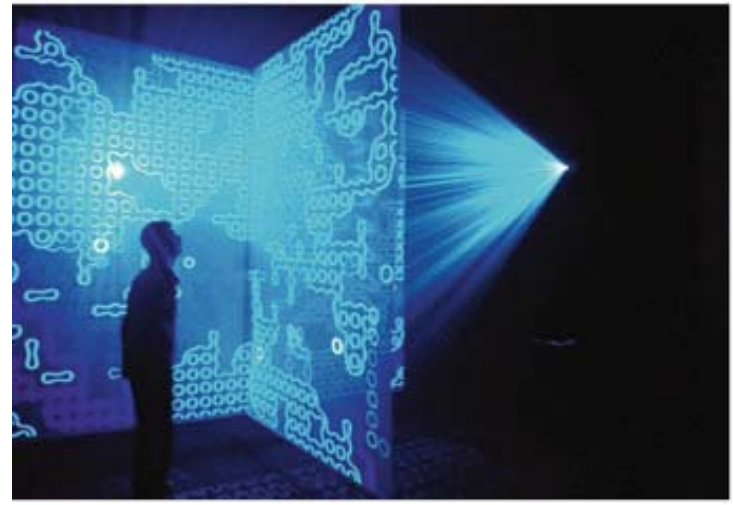

(e)

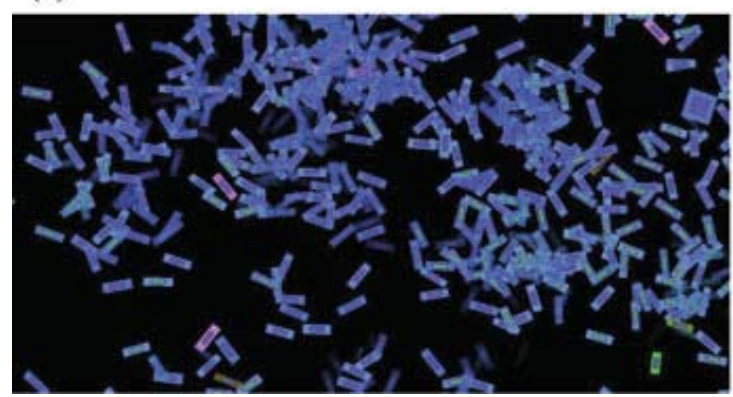

(b)

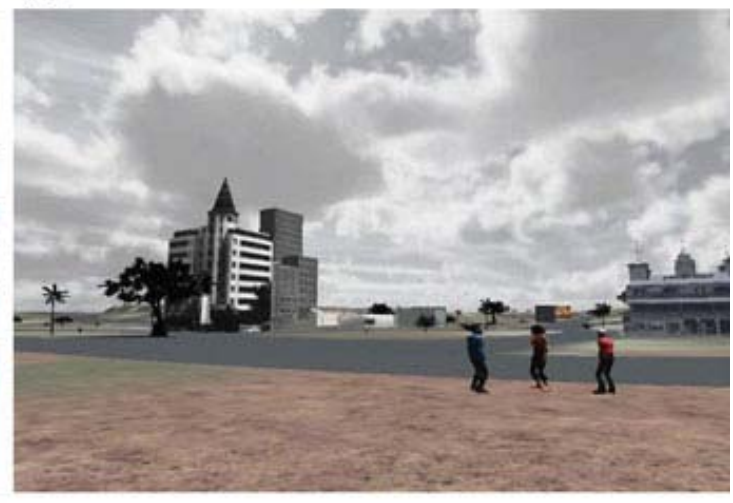

(d)

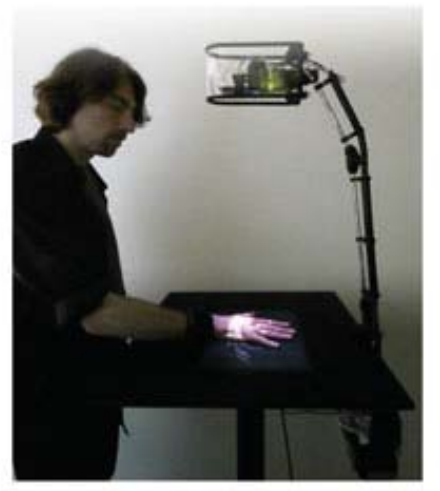

(f)

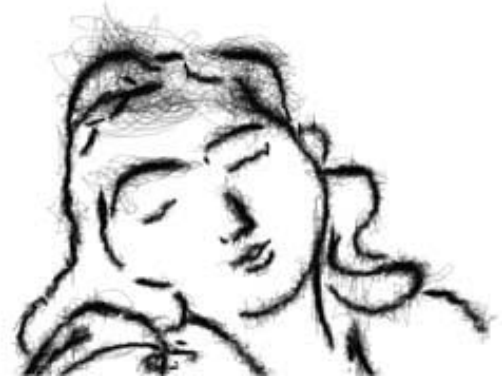

Fig. 9 The versatility of CEs: (a) Stills from Vishnu's Dance of Life and Death, a generative choreography in a virtual environment (Antunes \& Leymarie, 2012); The sequences of gestures and movements are created in unexpected ways by reflecting the interior dynamics and workings of a CE in operation; (C) Antunes \& Leymarie, 2012. (b) Where is Lourenço Marques? a virtual world where a population of gregarious humanoids is animated by a CE (Antunes, 2012; Antunes \& Leymarie, 2013); (C) Antunes \& Leymarie, 2012. (c) Jon McCormack's Eden (2004, detail), evolutionary ecosystem installation using multiple projectors and screens, with "creatures" improving their "singing" to attract visitors to their vicinity; (c) 2004 Jon McCormack (McCormack, 2001). (d) In Cycles' installation, the hand of the visitor is used as display; (C) 2009 Daniel Bisig (Bisig \& Unemi, 2010). (e) Detail of Pandemic (Dorin, 2012), an installation where creatures spread among themselves colourful "diseases" brought by the human visitors of the installation; (C) Alan Dorin, 2012. (f) Drawing produced by swarmic entities while searching for "energy" bits specially located in the canvas (Al-Rifaie \& Bishop, 2013); (C) Al-Rifaie \& Bishop, 2013 


\subsection{CEs and Virtual Worlds}

How do CEs inform Virtual Worlds? Based on the survey we conducted we can shortlist a number of characteristics and directions to exploit and explore further: (i) first and foremost is the autonomy of the system, which is formed by communities of agents, self-motivated and with various and varying behaviors [e.g. Eden (McCormack, 2001)]; (ii) moreover, such agents forming communities can have multiple representations and change over time (in the audible and/or visual domains) — such as being a youth in the early stages of a performance and become later an adult [e.g. xTNZ (Antunes \& Leymarie, 2008)]; (iii) additionally, as the first genre of EvoArt implies, agents can evolve over generations, by means of genetics and evolution via natural selection [e.g. Senhora da Graça (Antunes \& Leymarie, 2010)]; (iv) CEs can be modulated by user inputs, such as when agents are added and removed by the user's actions, who can further interact with them and their resources or even modify their genetic properties [e.g. A-Volve (Sommerer \& Mignonneau, 1994)[; (v) CEs can be controlled by external sources, such as weather conditions (Hutzler et al., 2000) or stock market exchange data [e.g. Black Sholes (Portway et al., 2004; Demos, 2012)].

As discussed previously, a critical aspect of a CE lies in its plasticity. As our study shows, CEs form a basis which is current in the production of a diverse and wide range of artistic outcomes. Virtual World developers can rely on this basis and incorporate CEs in their methodology and toolbox of proven technologies and art praxis. Examples of CEs combined with Virtual Worlds also illustrate the potentials of bringing together these two realms. Examples range from the abstract "vivid painting in motion" (Lioret, 2012), such as in Cycles (Bisig \& Unemi, 2010), to food-chains composed of autonomous NPCs acting as herbivores or carnivores and roaming in a virtual space [e.g. in Technosphere (Prophet, 1996)], to the animation of performing and improvising dancing avatars (e.g. in Vishnu's Dance of Life and Death (Antunes \& Leymarie, 2012), Fig. 9a), to talkative gregarious humanoid avatars inhabiting a lost city (e.g. in Where is Lourenço Marques? (Antunes, 2012; Antunes \& Leymarie, 2013), Fig. 9b).

\section{Conclusion}

We have looked at the context and features of artworks produced with CEs, as these have been presented to public audiences over the last two decades. The core of our study is a survey on the structure and attributes of artworks produced using a CE as framework, covering 40 published works through 20 years of praxis. We discussed and compared these works in terms of three categories of variables (contextual, interactivity and format). In terms of Contextual variables, our analysis shows that a large majority of works operate autonomously, with some inputs provided by the audience and are focused around the visualisation of life processes. In terms of 
Interactivity, almost all works involve visualisation, sonification or a combination thereof, and nearly half the projects involve the audience in influencing CEs' outcomes. Finally, in terms of Formal variables, a majority of works are exhibited in gallery spaces, and are set at the human scale (rather than say, the architectural scale). Forms and geometries used tend to be abstract rather than photo-realistic or purely representational.

Future projects could demarcate themselves from the works we surveyed by in particular: (i) further explore the use of external inputs (rather than mostly having an audience influence a CE's outcomes), (ii) allow users to reconfigure a CE's settings and evolution, (iii) give more control to users in accessing hidden levels or yet undiscovered areas of a Virtual World (and maintain interest), alike in the design of commercial games, (iv) use advances in real time graphics, integrate more special effects, and perhaps explore further the use of 3D visualisations (e.g. with autostereoscopy and new wearable AR and VR systems such as Google glasses and their descendants), (v) produce multimedia works which integrate more intimately the different modalities, in particular the visual and aural (which tend to be left independent in their production), and also integrate haptics and gestures thanks to recent and foreseeable developments in hardware and software, (vi) favour and explore further the dimensions of the environment, society, the political or the economy, rather than the prevalent life process referential, (vii) promote works to the macro scales, such as the architectural (e.g. projecting on the facades of buildings and monuments) or urban (e.g. using mobile platforms).

In summary, CEs provide a rich framework in support of EvoArt which has been explored in multiple formats and as part of diverse artistic agendas. By studying these artefacts we can identify a number of techniques and approaches which might inform the development of future Virtual Worlds, and augment these with evolutionary mechanisms of natural selection and genetics, use CEs to create generative soundscapes, or even use CEs in Virtual Worlds as abstract generative engines and explore their dynamics as a way to animate agents with unique, even human-like, behaviors (Antunes \& Leymarie, 2013).

\section{References}

Aarseth, E. (1997). Cybertext: Perspectives on ergodic literature. Baltimore, MD: The Johns Hopkins University Press.

Al-Rifaie, M., \& Bishop, M. (2013). Swarmic sketches deploy attention mechanism. In P. Machado, J. McDermott, \& A. Carballal (Eds.), Proceedings of the Second International Conference on Evolutionary and Biologically Inspired Music, Sound, Art and Design, Evomusart 2013 (Vol. 7834, pp. 85-96). Heidelberg: Springer.

Annunziato, M. (1998). The Nagual experiment. In Proceedings of the First International Conference on Generative Art (pp. 241-250).

Annunziato, M., \& Pierucci, P. (2000). Towards artificial societies. In Proceedings of the Third International Conference on Generative Art.

Antunes, R. F. (2012). Where is Lourenço Marques? A mosaic of voices in a 3D virtual world. Leonardo Electronic Almanac (Touch and Go), 18(3), 114-121. 
Antunes, R. (2014). On computational ecosystems in media arts. PhD thesis, Goldsmiths College, University of London.

Antunes, R. F., \& Leymarie, F. F. (2008). xTNZ-an evolutionary three-dimensional ecosystem. In A. Barbosa (Ed.), Proceedings of the Fourth International Conference on Digital Arts, Artech2008 (pp. 201-204).

Antunes, R. F., \& Leymarie, F. F. (2010). Epigenetics as aesthetic instrument in a generative virtual ecosystem. In L. Valbom (Ed.), Proceedings of the Fifth International Conference on Digital Art Artech 2010 (pp. 172-176).

Antunes, R. F., \& Leymarie, F. F. (2012). Generative choreography: Animating in real time dancing avatars. In P. Machado, J. Romero, \& A. Carballal (Eds.), Proceedings of the First International Conference on Evolutionary and Biologically Inspired Music, Sound, Art and Design, Evomusart 2012 (pp. 1-10).

Antunes, R. F., \& Leymarie, F. F. (2013). Real-time behavioral animation of humanoid non-player characters with a computational ecosystem. In R. A. et al. (Ed.), 13th Conference on Intelligent Virtual Agents (iva 2013), Inai 8108 (pp. 382-395). Heidelberg:Springer.

Arts, E. (2009). Second life masterpieces-Starax Statosky: Second Life Giotto. Retrieved from http://sichelseifert.wordpress.com/2009/01/05/starax-statosky-second-life-giotto/

Bentley, P., \& Corne, D. (2002). Creative evolutionary systems. San Diego, CA: Academic.

Berry, R., Rungsarityotin, W., \& Dorin, A. (2001). Unfinished symphonies-songs of 3112 worlds. In B. et al (Ed.), Ecal 2001 artificial life models for musical applications (pp. 51-64). Konferensbidrag

Bisig, D., \& Unemi, T. (2010). Cycles-blending natural and artificial properties in a generative artwork. In Proceedings of the xiii Generative Art Conference. Milano, Italy (pp. 140-154). Retrieved from http://lab30.de/2010/en/exhibition/97

Boden, M. A., \& Edmonds, E. A. (2009). What is generative art? Digital Creativity, $20(1 \& 2)$, 21-46.

Bornhofen, S., Heudin, J., Lioret, A., \& Torrel, J. (Eds.). (2012). Virtual worlds: Artificial ecosystems and digital art exploration. Paris: Science ebooks.

Bornhofen, S., Gardeux, V., \& Machizaud, A. (2012). From swarm art toward ecosystem art. International Journal of Swarm Intelligence Research, 3(3), 18.

Bown, O., \& McCormack, J. (2010). Taming nature: Tapping the creative potential of ecosystem models in the arts. Digital Creativity, 21(4), 215-231.

Brown, R., Aleksander, I., MacKenzie, J., \& Faith, J. (2001). Biotica: Art, emergence and artificial life. London: Art Books International.

Carvalhais, M. (2010). Towards a model for artificial aesthetics. In Proceedings of ga2010-xiii Generative Art Conference.

Chen, C.-Y., \& Hoyami, J.-C. (2007). Autonomous systems for interactive digital art. In Tenth Generative Art Conference ga2007.

Dahlstedt, P., \& Nordahl, M. G. (2001, June). Living melodies: Coevolution of sonic communication 34(3)

Damer, B., Marcelo, K., Revi, F., Furmanski, T., \& Laurel, C. (2005). Nerve garden: Germinating biological metaphors in net-based virtual worlds. In A. Adamatzky \& M. Komosinski (Eds.), Artificial life models in software (pp. 67-80). London: Springer.

Demos, T. J. (2012, April). Art after nature. Artforum, pp. 191-198.

Dorin, A. (2003). Meniscus-exhibited at the Experimenta House of Tomorrow. Retrieved 5 Sept-3 Oct 2003, from http://www.csse.monash.edu.au/ aland/meniscus.html

Dorin, A. (2005). Artificial life, death and epidemics in evolutionary, generative electronic art. In F. Rothlauf et al. (Ed.), Proceedings of the Third European Workshop on Evolutionary Music and Art, Applications of Evolutionary Computing: Evoworkshops (pp. 448-457). Berlin, Heidelberg: Springer.

Dorin, A. (2006). Plague, exhibited at Satellite, Australian Pavillion, for Shanghai Bienalle. Retrieved September 3-27, 2006, from http://www.csse.monash.edu.au/aland/plague.html 
Dorin, A. (2009a). Constellation - exhibited at Biotope, Cube 37 Gallery, Frankston, Victoria, Australia. Curated by CEMA. Retrieved 13 July-9 August, from http://www.csse.monash.edu. au/aland/constellation.html

Dorin, A. (2009b). Habitat: Engineering in a simulated audible ecosystem. In M. Giacobini et al. (Eds.), Applications of evolutionary computing (Vol. 5484, pp. 488-497). Berlin, Heidelberg: Springer.

Dorin, A. (2012). Pandemic - generative software installation, Exhibited: Bouillants 4, Vern-surSeiche, Brittany, France, Gaetan Allin and Laurent Dupuis (artistic directors), 22 April20 May

Driessens and Verstappen. (2006). E-volver-exhibited at the new Onderzoeksgebouw (research building) of the Leiden University Medical Center, in Amsterdam, fromhttp://classic.skor.nl/ page $/ 2429 /$ nl?lang=en

Eldridge, A., \& Dorin, A. (2009). Filterscape: Energy recycling in a creative ecosystem. In M. Gia-cobini (Ed.), Proceeding of Evoworkshops'09 Proceedings of the Evoworkshops 2009 on Applications of Evolutionary Computing (pp. 508-517). Heidelberg: Springer.

Eldridge, A., Dorin, A., \& McCormack, J. (2008). Manipulating artificial ecosystems. In M. Giacobini et al. (Eds.), Applications of evolutionary computing (Vol. 4974, pp. 392-401). Berlin, Heidelberg: Springer.

Heudin, J.-C. (2012). Lifedrop: A drop of life on the web. In S. Bornhofen, J. Heudin, A. Lioret, \& J. Torrel (Eds.), Virtual worlds: Artificial ecosystems and digital art exploration (pp. 79-98). Paris: Science ebooks.

Hutzler, G., Gortais, B., \& Drogoul, A. (2000). The garden of chances: A visual ecosystem. Leonardo, 33, 101-106. MIT Press Journals.

Ji, H. (2012). Artificial natures: Creating nature-like aesthetic experiences through immersive artificial life worlds. Ph.D. Dissertation, University of California, Santa Barbara.

Ji, H., \& Wakefield, G. (2012). Virtual world-making in an interactive art installation: Time of doubles. In S. Bornhofen, J. Heudin, A. Lioret, \& J. Torrel (Eds.), Virtual worlds: Artificial ecosystems and digital art exploration (pp. 53-70). Paris: Science ebooks.

Kowaliw, T., McCormack, J., \& Dorin, A. (2011, April). An interactive electronic art system based on artificial ecosystemics. In 2011 I.E. Symposium on Artificial life (alife) (pp. 162-169). doi: 10.1109/AL-IFE.2011.5954645

Krauss, R. E. (2011). Under blue cup. Cambridge, MA: MIT Press.

Lambert, N., Latham, W., \& Leymarie, F. F. (2013). The emergence and growth of evolutionary art 1980-1993. Leonardo, 46(4), 367-375.

Latham, W. (1989). Form synth: The rule-based evolution of complex forms from geometric primitives. In J. Lansdown \& R. A. Earnshaw (Eds.), Computers in art, design and animation (pp. 80-108). New York: Springer.

Lenton, T. M., \& Lovelock, J. E. (2001). Daisyworld revisited: Quantifying biological effects on planetary self-regulation. Tellus B, 53(3), 288-305.

Lioret, A. (2012). Artificial life creation for cinema. In S. Bornhofen, J. Heudin, A. Lioret, \& J. Torrel (Eds.), Virtual worlds: Artificial ecosystems and digital art exploration (pp. 23-38). Paris: Science ebooks.

McCormack, J. (1994). TURBULENCE an interactive installation exploring artificial life. In Visual Proceedings of ACM Siggraph 94 (pp. 182-183). Orlando, FL: Academic Press

McCormack, J. (2001). Eden: An evolutionary sonic ecosystem. In J. Sosik \& P. Kelemen (Eds.), Lecture notes in artificial intelligence (Vol. 2159, advances in artificial life, pp. 133-142). Berlin: Springer.

Mccormack, J. (2005). Open problems in evolutionary music and art. In F. Rothlauf et al. (Eds.), Applications of evolutionary computing, (evomusart 2005) (pp. 428-436). Berlin: Springer.

McCormack, J. (2012). CodeForm, Virtual Ecosystem of Artificial Life, Commission for the Ars Electronica Museum, Linz, Austria, from http://jonmccormack.info/ jonmc/sa/artworks/ codeform/ 
McCormack, J., \& Bown, O. (2009). Life's what you make: Niche construction and evolutionary art. In M. Giacobini et al. (Eds.), EvoWorkshops (LNCS 5484, pp. 528-537). Berlin: Springer.

Mitchell, J. D., \& Lovell, R. E. (1995). Environment for the interactive design of emergent art. In Isea 95: Sixth international symposium on electronic arts (pp. 17-21). Montreal, Canada

Portway, J., Autogena, L., Hoile, C., \& Riley, T. (2004). Black shoals: Stock Market Planetarium, from www.blackshoals.net

Prophet, J. (1996). Sublime ecologies and artistic endeavors: Artificial life and interactivity in the online project "TechnoSphere". Leonardo, 29(5), 339-344. Retrieved from http://www.jstor. org/stable/1576397.

Railsback, S. F., \& Grimm, V. (2011). Agent-based and individual-based modeling: A practical introduction. Princeton, NJ: Princeton University Press.

Ray, T. S. (1995). An evolutionary approach to synthetic biology: Zen and the art of creating life. Artificial Life 1(1/2): 179-209. In C. G. Langton (Ed.), Artificial life, an overview (pp. 179-209). The MIT Press.

Romero, J., \& Machado, P. (Eds.). (2007). The art of artificial evolution: A handbook on evolutionary art and music. Berlin: Springer.

Saruwatari, T., Toqunaga, Y., \& Hoshino, T. (1994). ADIVERSITY: Stepping up trophic levels. In R. A. Brooks \& P. Maes (Eds.), Proceedings of the Fourth International Workshop on the Synthesis and Simulation of Living Systems (pp. 424-429).

Sommerer, C., \& Mignonneau, L. (1994). A-Volve: A real-time interactive environment. In ACM Siggraph Visual Proceedings (pp. 172-173).

Sommerer, C., \& Mignonneau, L. (2000). Life Spacies II. In G. Stocker \& C. Schöpf (Eds.), Ars Electronica 2000 Next Sex (p. 392). Vienna, New York: Springer.

Sommerer, C., Mignonneau, L., \& Lopez-Gulliver, R. (2001). IKI-IKI Phone-A multiuser Alife art game for mobile phones. In IEEEE International Conference on Multimedia and Expo (ICME), Tokyo, Japan (pp. 152-155).

Spinster, A. (2007). Exhibited at down to Earth, Oxford House Art (Oh! Art), from http://www. turbulence.org/blog/archives/002602.html

Todd, S., \& Latham, W. (1992). Evolutionary art and computers. San Diego, CA: Academic Press.

Ventrella, J. (2005). GenePool: Exploring the interaction between natural selection and sexual selection. In A. Adamatzky \& M. Komosinski (Eds.), Artificial life models in software (pp. 81-96). Berlin: Springer. Retrieved from http://www.ventrella.com/alife/genepool.pdf.

Wakefield, G. (2012). Real-time meta-programming for open-ended computational arts. Ph.D. Dissertation, University of California, Santa Barbara.

Wakefield, G., \& Ji, H. (2009). Artificial nature: Immersive world making. In R. A. Brooks \& P. Maes (Eds.), Applications of evolutionary computing (Lncs 5484, pp. 377-381). Berlin: Springer.

Watson, T., \& Gobeille, E. (2007). Exhibited at DigiPlaySpace, from http://www.theowatson. com/sitedocs/work.php?id=41

Watson, A. J., \& Lovelock, J. E. (1983). Biological homeostasis of the global environment: The parable of Daisyworld. Tellus B, 35(4), 286-289.

Whitelaw, M. (2004). Metacreation: Art and artificial life. Cambridge, MA: MIT Press.

Yaeger, L. (1994). Computational genetics, physiology, metabolism, neural systems, learning, vision, and behavior on Polyworld: Life in a new context. In C. Langton (Ed.), Artificial life III, Santa Fe Institute Studies in the Sciences of Complexity (Vol. xvii, pp. 263-298). Reading, MA: Addison-Wesley. 